\title{
GAS Y ELECTRICIDAD. LA EVOLUCIÓN DE SU TECNOLOGÍA A PARTIR DE LOS ARTÍCULOS Y NOTICIAS APARECIDAS EN PUBLICACIONES PERIÓDICAS DE CARÁCTER TÉCNICO EN ESPAÑA Y FRANCIA ENTRE 1855 Y 1910
}

\author{
Joan Carles Alayo Manubens \\ Universitat Politècnica de Catalunya \\ Email: jc.alayo@enginyers.net \\ ORCID iD: https://orcid.org/0000-0002-4862-9559 \\ Francesc Xavier Barca Salom \\ Universitat Politècnica de Catalunya \\ Email: francesc.barca@gmail.com \\ ORCID iD: https://orcid.org/0000-0002-6914-6564
}

Recibido: 14 Abril 2021; Aceptado 28 Mayo 2021

Cómo citar este artículo/Citation: Alayo Manubens, Joan Carles; Barca Salom, Francesc Xavier (2021) "Gas y electricidad. La evolución de su tecnología a partir de los artículos y noticias aparecidas en publicaciones periódicas de carácter técnico en España y Francia entre 1855 y 1910", Asclepio, 73 (2): p565. https://doi.org/10.3989/asclepio.2021/23

RESUMEN: Tanto el proceso de obtención del gas de hulla como los fenómenos eléctricos fueron estudiados de una forma metódica a partir del siglo XVIII. Pero, fue a principio del siglo siguiente que el gas empezó a utilizarse en el alumbrado, y años después, en desarrollar trabajo mecánico, o en calentar fluidos. En el último tercio del siglo, el desarrollo de la electricidad fue sustituyendo algunas de las aplicaciones que proporcionaba el gas. Este proceso quedó reflejado en una gran cantidad de escritos y publicaciones que difundieron los nuevos conceptos y las formas de obtención y de utilización de estas fuentes.

En este artículo mostramos los resultados de un estudio cuantitativo de los artículos sobre gas y electricidad en la literatura industrial en un periodo en que los caminos de ambas fuentes empezaban a divergir. Como ejemplo nos detenemos también en dos casos concretos: algunos procedimientos alternativos de producción de gas y el auge de la electricidad.

PALABRAS CLAVE: Gas; Electricidad; Revistas Técnicas; Transferencia Tecnología.

\section{GAS AND ELECTRICITY. THE EVOLUTION OF ITS TECHNOLOGY BASED ON THE PAPERS AND NEWS APPEARED IN PERIODICAL TECHNICAL PUBLICATIONS IN SPAIN AND FRANCE BETWEEN 1855 AND 1910}

ABSTRACT: Both the process of obtaining coal gas and electrical phenomena were studied in a methodical way from the eighteenth century. But it was at the beginning of the following century that gas began to be used in lighting, and years later, in developing mechanical work, or in heating fluids. In the last third of the century, the development of electricity was replacing some of the applications that gas provided. This process was reflected in many writings and publications that spread the new concepts and the ways of obtaining and using these sources.

In this article we show the results of a quantitative study of the articles on gas and electricity in the industrial literature in a period when the paths of both sources were beginning to diverge. As an example, we also look at two specific cases: some alternative gas production procedures and the electricity boom.

KEY WORDS: Gas; Electricity; Technical Magazines; Technology Transfer. 


\section{INTRODUCCIÓN}

En el siglo XIX el gas de hulla empezó a utilizarse como forma energética, capaz de proporcionar luz, desarrollar trabajo mecánico, calentar fluidos y proporcionar calefacción. Ya es conocido que este desarrollo se inició en Europa, en concreto en Francia e Inglaterra y se extendió por el resto de países, atravesando el Atlántico para instalarse también en los Estados Unidos.

Con esta nueva tecnología, ciertamente no muy complicada, que necesitaba el carbón como producto principal, muchas ciudades adoptaron el gas principalmente para mejorar el alumbrado público de sus calles y plazas. En España se conoce que, en 1807, se hicieron ensayos para la obtención de gas para iluminación, en Granada y en Cádiz, pero la primera instalación se hizo en una de las salas de dibujo de la casa Lonja de Mar de Barcelona, que empezó a funcionar la noche del 24 de junio de 1826. Años más tarde, en Madrid, se hizo una instalación transitoria para festejar el nacimiento de María Luisa Fernanda, hija del rey, era el 2 de marzo de 1832 y un año después se iniciaba la instalación que había de iluminar con gas el Palacio Real. A partir de estas primeras actuaciones el gas manufacturado fue considerado como elemento de iluminación para el alumbrado público y privado, siendo adoptado por la ciudad de Barcelona en 1842, en Valencia en 1844, en Cádiz en 1846, en Madrid en 1847 y seguirían bastantes ciudades más.

A mediados del mismo siglo XIX la electricidad irrumpía en el panorama científico e industrial, con su capacidad de iluminación y se convirtió en alternativa al gas como agente iluminante. Su desarrollo tecnológico se había gestado desde el siglo XVII, pero fue en el siglo XIX cuando se manifestó con más ímpetu con las pilas y artefactos luminosos que hacían posible su uso. En España el uso de la electricidad en el alumbrado empieza en 1851, cuando en el mes de mayo se efectúan unas pruebas utilizando la pila eléctrica y la luz de arco, en la Universidad de Santiago y en noviembre del mismo año se realizó otro experimento en la Universidad de Barcelona. Pero el uso de las pilas eléctricas para el alumbrado fue muy limitado. El arco voltaico, el sistema de iluminación que se inició con el uso de la electricidad, consumía mucha energía, el desgaste de la pila era rápido, y en consecuencia era muy caro alumbrarse con pilas, favoreciendo el uso del gas para la iluminación que siguió desarrollándose. El alumbrado eléctrico sólo comenzó a ser considerado económico cuando a partir del año 1866 aparecieron las máquinas eléctricas, como la construida por Wilde, y años después con los perfeccionamientos de Siemens, Gramme, y muchos otros.

Las máquinas eléctricas, los reguladores de arco, las lámparas incandescentes, y posteriormente los transformadores eléctricos, permitieron que la electricidad consolidase toda una estructura técnica que, a similitud del gas, el norteamericano T.A. Edison utilizó por primera vez con éxito en dos pequeños barrios, en Londres y en Nueva York, en el año 1882 , pero en corriente continua.

Ello supuso tener dos sistemas de producción de energía o, mejor dicho, de transformación de energía en luz, que podían ser, a la vez, complementarios o antagónicos. Por ejemplo, si una fábrica tenía como fuente de energía una máquina de vapor o un motor hidráulico, podía acoplar una dinamo con poco gasto adicional y le permitía el uso de la electricidad. Entonces el coste del alumbrado eléctrico le salía competitivo, alrededor de las 2 pesetas por hora, mientras que el alumbrado por gas le costaba unas 3,5 pesetas por hora, y, además, el alumbrado eléctrico le aportaba mayor luminosidad. Por otro lado, para hacer funcionar una dinamo podía utilizarse un motor de gas, que fue introducido en los años 1870, ya que estos motores tenían un coste de instalación mucho más reducido que una máquina de vapor, he aquí ejemplos de antagonismo y de complementariedad.

Estos avances científicos y técnicos fueron quedando recogidos en los diversos tratados y publicaciones que fueron apareciendo. En España, en lo que se refiere al gas la primera que creemos se editó fue: Breve noticia sobre el alumbrado por gas, de autor casi desconocido (pues firma A.V.), editada en Madrid en 1832 y sin ser un texto técnico explica sucintamente el sistema de iluminación por gas y cómo se utilizó en la capital para la iluminación de las calles en aquel año. La primera noticia de una publicación sobre electricidad de autor español, fue: Physica Eléctrica o Compendio donde se explican los maravillosos phenomenos de la Virtud Eléctrica, de Benito Navarro y Abel de Beas, publicada en 1752, y explica los experimentos que eran habituales en aquella época, publicación que fue contestada por José Manuel de Cuevas en: Dudas sobre la Phisica Eléctrica del Doctor Benito Navarro de 1754, y aunque más antiguo era el manuscrito de 1751 de Pedro Rodríguez de Campomanes: Discurso sobre la 
electricidad o Rechazar del Aire, la publicación de Navarro era más importante.

Lo cierto es que la bibliografía gasista y eléctrica de autores españoles, o editada en español, es importante y muestra que los avances de esta rama de la ciencia fueron divulgados en España. Pero tanto como los libros, también lo fueron las publicaciones periódicas que surgieron para dar conocimiento de las artes industriales que a lo largo del siglo XIX se iban desarrollando. Publicaciones que difundieron nuevos conceptos, formas de obtención y utilización de las artes industriales y también con sus aportaciones fueron definiendo, analizando, configurando y difundiendo las tecnologías que serían aplicadas en la obtención y distribución del gas manufacturado, así como en la producción y utilización de la electricidad. Este es el objeto de nuestra investigación, con especial atención a publicaciones periódicas de España y Francia entre 1855 y 1910.

\section{EL PANORAMA DE LAS PUBLICACIONES EN ESPAÑA}

Con el progreso de las ciencias, en el siglo XVIII y principalmente en el siglo XIX, aparecerán publicaciones que tratarán -con periodicidad diversa (semanal, quincenal o mensual)- de reflejar este avance, así como de la evolución industrial. Descubrimientos, ensayos, exposiciones, todo quedaría expuesto en estas publicaciones que iniciaron su actividad abarcando todas las ramas de la ciencia y la tecnología, y con el tiempo irían apareciendo otras que concretarían o se especializarían más en uno o en varios ámbitos afines de la ciencia o la tecnología.

En Europa muchas son las publicaciones que con carácter científico comienzan a aparecer desde mediados del siglo XVIII, como: Miscellanea philosophico-mathematica Societatis privatae Taurinensis (Turín,1759), Journal des beaux-arts et des sciences (París, 1768), Acta Academiae Scientiarum Imperiales Petropolitanae (San Petersburgo,1778), Annales de Chimie (París, 1789), por citar algunas de las que inician esta práctica. Y aun cuando algunas de las revistas tengan escasa relevancia como medio de transmisión de información científica, su existencia indica la importancia que en la época se daba a la ciencia.

Sin ánimo de efectuar ninguna reseña sobre las publicaciones extranjeras, una de las primeras que aparece en el ámbito de las tecnología seria, The Philosophical magazine: comprehending the va- rious branches of science, the liberal and fine arts, agriculture, manufactures and commerce (Londres, 1798) y que continuaría en 1813 con el nombre de The Philosophical magazine and journal al unirse con A Journal of natural philosophy, chemistry and the arts y posteriormente siguió con otros nombres de cabecera hasta el siglo XX.

También merece ser destacada la publicación anual The Franklin Journal, and American Mechanics Magazine (Filadelfia, 1826), para dar relieve a todas las ciencias y técnicas en los Estados Unidos, o The Engineer (Londres, 1856) que sigue aun publicándose en la actualidad.

En España, a pesar de su limitada estructura científico-técnica, las publicaciones extranjeras irían penetrando, se consolidarían como vehículo de conocimiento e incentivarían la aparición de publicaciones propiamente españolas o editadas en España, con el interés por conocer nuevas mejoras técnicas, introducir los avances en la mecanización y las manufacturas.

Muchas tendrían una corta duración, como: Anales de historia natural (Madrid, 1799) a la que siguió Anales de Ciencias naturales. Otras fueron, Variedades de ciencias, literatura y artes (Madrid, 1803), o Memorias de Agricultura y Artes (Barcelona, 1815), o Crónica científica y literaria (Madrid, 1817), o Periódico universal de ciencias, literatura y artes (Barcelona, 1821), pero todas ellas representarían el interés por divulgar los avances científicos y técnicos en las primeras fases de la industrialización.

También las Academias de Ciencias, con sus memorias, impulsarían la literatura científica, las primeras fueron las Memorias de la Academia de Ciencias Naturales y Artes de Barcelona (Barcelona,1835) o la Revista de los progresos de las ciencias exactas, físicas y naturales de la Real Academia de Ciencias Exactas, Físicas y Naturales (Madrid, 1850), y otra publicación que merece ser destacada por su línea de continuidad, aunque ciertamente se separe estrictamente de la función científico-técnica es Memorial de ingenieros: memorias, artículos y noticias interesantes al arte de la guerra en general y a la profesión de ingenieros en particular (Madrid, 1846).

Pero será a partir de 1850 cuando las publicaciones de marcado carácter técnico comenzaran a aparecer con más arraigo, como fue la Revista minera: periódico científico e industrial (Madrid, 1850), que con distintas cabeceras: Revista minera y meta- 
lúrgica; Revista minera, metalúrgica y de ingeniería; Revista minera, científica, industrial y mercantil, se editaría hasta 1936. O la Revista de obras públicas (Madrid, 1853), que sigue vigente y que a partir de 1924 la publica la Escuela Especial de Ingenieros de Caminos, Canales y Puertos; También se puede destacar la Gaceta de los caminos de hierro, industria, minas, gas, seguros y sociedades de Crédito (Madrid, 1856)

Publicaciones que aportaron al conjunto industrial español, información de autores españoles y de artículos captados de publicaciones europeas, sobre nuevas técnicas, y en lo que concierne a nuestro trabajo, sobre las innovaciones en la industria del gas y de la electricidad.

Sin embargo, durante todo el siglo XIX no encontramos en España ninguna publicación específica sobre el gas manufacturado. Como industria basada en la química, las novedades (pocas), vinculadas con la fabricación, purificación y distribución del gas, se situarán en las publicaciones de carácter industrial, más que en las también pocas publicaciones dedicadas a la industria química.

En España la publicación específica sobre química se inicia con Anales de química: monitor de química y farmacia y de las ciencias auxiliares (Madrid,1867), pero finalizará a los pocos años de edición. Sin embargo, el gas existe, y aparece en las revistas de una forma u otra. Merece ser destacado el artículo sobre el procedimiento de obtención de gas que apareció en Memorias de Agricultura y Artes, en abril de 1818, cuyo título parece alejado de lo que es una fábrica de gas, pero contiene una descripción exhaustiva de lo que es y cómo se fabrica este fluido energético (Barca y Alayo, 2019).

El gas hidrógeno sacado de la hornaguera se puede conservar por todo el tiempo que se considere necesario: se deja conducir a largas distancias por tubos y conductos como el agua, pasando por ellos con la misma regularidad y facilidad que este fluido, y se distribuye también en infinidad de ramificaciones. [...] : si se le acerca una vela encendida se inflama instantáneamente sin despedir olor, produciendo una luz viva y brillante. [...] La brillantez de esta es superior a la de las candelas, de los quinquets [sic] y de las lámparas de Angard [sic] ${ }^{1}$ arde igualmente que los picos de los tubos que la mantienen estén en posición vertical o en situación horizontal, lo que no permite ni el aceite, ni la cera, ni otros combustibles que se derraman o se derriten, circunstancia muy apreciable en las arañas que sirven para iluminar templos y salas. (Santponç, 1818, 225-236).
Figura 1: Máquina hidrostática que sirve para la formación y distribución de gas hidrogeno que ilumina las calles de Londres, plazas públicas y edificios. (Fuente: Santponç, 1818, lam. 69, p.292).

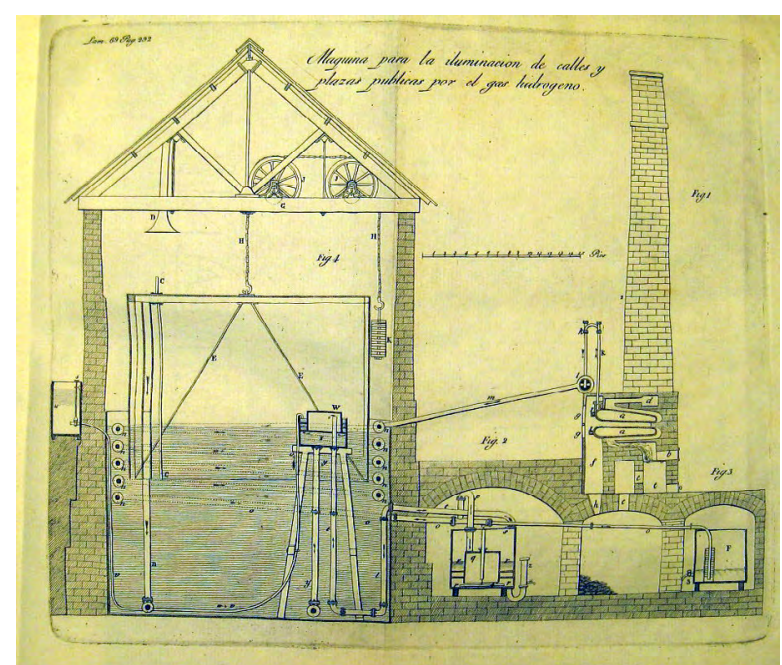

O también este otro relato sobre la iluminación callejera:

Y toda esta escena, todo este espectáculo semi-diabólíco, semi-fantástico, que recuerda las fraguas de Vulcano, está iluminado por los faroles de gas del paseo; por los de aceite de la verbena, y por los rojos penachos de fuego chispeante que brotan de los tubos de los hornos buñoleros, envueltos en borbotones de humo, que ascienden formando densas espirales y se disipan con el vientecillo que corre de la parte del Retiro. ${ }^{2}$

No sucedió lo mismo con la electricidad, como ya es evidente, pues esta rama de la física al poco tiempo de empezar a desarrollarse tuvo publicaciones periódicas que siguieron sus avances y nuevas instalaciones, la primera fue La Electricidad (Barcelona, 1883), que exponía, como bien decía, sus progresos científicos e industriales, posteriormente aparecería La Ciencia Eléctrica (Madrid, 1890).

\section{LAS PUBLICACIONES COMO VEHÍCULO DE TRANSFERENCIA DE CONOCIMIENTOS}

El progreso de las artes industriales en Europa y Estados Unidos tuvo un gran desarrollo, ello combinado con la celebración de Exposiciones Internacionales y Universales representó el aproximarse de los avances en todas las ramas de la tecnología y las publicaciones que fueron apareciendo se transformaron en el vehículo principal de difusión.

En lo que se refiere al gas la primera que se editó fue Journal of Gas Lighting (Londres, 1849), que empe- 
zó a tratar de los adelantos en la producción y distribución del gas, así como la distribución de agua, y que ya en 1878 también incorporaba el alumbrado eléctrico en su índice de artículos de interés. Un año después aparecía Le Gaz (1857), Journal des consommateurs des gaz d'éclairage et de chaufagge, que fue publicada en París hasta 1914, cuando la Primera Guerra Mundial provocó su cierre. Pero posteriormente reanudaría la publicación con el título Le Gaz et l'Électricité, Organe mensuel des interets de l'industrie gaziere, en 1922, para sucumbir de nuevo en 1939 ya definitivamente. No obstante, en ambas, aunque más en su segunda época, ya quedaba de manifiesto que la electricidad también estaba presente en sus artículos.

Pero fue la electricidad lo que principalmente influyó en la aparición de publicaciones técnicas, cuando desde 1872 fueron apareciendo en diversos países, para corroborar que, como ciencia y tecnología, incidiría profundamente en toda la sociedad, quizás mucho más que el gas.

El conjunto de estas doce revistas recogidas en la tabla 1 concluye con una publicación editada en Barcelona por la Sociedad Española de Electricidad, para dar a conocer y difundir toda clase de noticias sobre esta nueva fuente de energía.

Con estos antecedentes, este artículo pretende mostrar, basándose en unas publicaciones seleccionadas, cuáles fueron y como se desarrollaron las aportaciones de técnicos y científicos en esta temática, presentando el estado de la cuestión en España, en la segunda mitad del siglo XIX, con una industria del gas ya en marcha y una electricidad en fase de penetración.

\section{LAS PUBLICACIONES ESTUDIADAS Y SU INTERÉS}

Para comprender el alcance y la repercusión que el gas y la electricidad tuvieron entre el colectivo de científicos y técnicos en el contexto de la Europa latina, se han seleccionado publicaciones técnicas exclusivamente generalistas, dejando de lado las especializadas en esas dos fuentes de energía.

Le Génie industriel, revue des inventions françaises et étrangères fue publicada en un periodo con el gas como centro del alumbrado, mientras que la electricidad aún no era una energía competidora, y como manifestaba en su portada incluía tecnología, mecánica, ferrocarriles, navegación, química, agricultura, minas, trabajos públicos y diversas artes, y también biografías de los inventores a fin de dignificar su tarea y potenciar el reconocimiento social, hasta el momento inexistente.

En el prólogo inicial del primer número se indicaba que no solo se proporcionaban las descripciones de los nuevos procesos, sino que se hacía hincapié en las ventajas que representaban. Para juzgar el mérito de estos inventos se iba a incluir unos resúmenes históricos de los procesos anteriores tanto si eran franceses como de otros países. Sus autores se comprometían también

Tabla 1. Las 12 primeras publicaciones específicas sobre electricidad hasta 1882.

\begin{tabular}{|c|c|c|}
\hline Nombre & Año de inicio & Publicada en .. \\
\hline The Telegraphic Journal and Electrical Rewiew & 1872 & Londres \\
\hline L' Électricité & 1876 & Paris \\
\hline The Electrician & 1878 & Londres \\
\hline La Lumiére Éléctrique & 1879 & Paris \\
\hline Electrichestvo & 1880 & Sant Petersburgo \\
\hline Elektrotechnische Zeitschrift & 1880 & Berlin \\
\hline Journal of the Society of Telegraph Engineers and Electricians & 1881 & Londres \\
\hline L'Electricien & 1881 & Paris \\
\hline Journal du Gaz et de l'Électricité & 1881 & Paris \\
\hline The Electrical World and Engineer & 1882 & Nueva York \\
\hline Electrical Review & 1882 & Chicago \\
\hline La Electricidad & 1882 & Barcelona \\
\hline
\end{tabular}


Tabla 2. Relación de publicaciones seleccionadas.

\begin{tabular}{|c|c|c|}
\hline Publicación & $\begin{array}{c}\text { Período de } \\
\text { años }\end{array}$ & Edición \\
\hline $\begin{array}{c}\text { Le Génie Industriel, revue des inventions françaises et étrangères } \\
\text { Portefeuille Economique des Machines, de l'outillage et du matériel }\end{array}$ & $1851-1870$ & París \\
Revista de Obras Públicas & $1857-1914$ & Paris \\
Gaceta industrial, económica y científica & $1865-$ & Madrid \\
Annales Industrielles & $1869-1894$ & Padrid \\
El Porvenir de la Industria & $1875-1900$ & Barcelona \\
Revista Tecnológico Industrial & $1878-$ & Barcelona \\
Industria e Invenciones & $1884-$ & Barcelona \\
\hline
\end{tabular}

en reseñar las patentes nacionales o extranjeras que habían sido otorgadas desde 1850 .

Los editores eran los hermanos Armengaud. Eugène Armengaud (1810-1891) era ingeniero industrial y profesor de dibujo de máquinas de Conservatoire $\mathrm{Na}$ tional des Arts et Métiers, y su hermano Charles Armengaud (1813-1893) era ingeniero civil. Nacidos en Ostende (Bélgica) los dos fundaron el primer despacho de ingenieros asesores para la protección de los derechos del inventor. Con esta publicación mensual (encuadernada en dos volúmenes al año, uno de enero a junio y otro de julio a diciembre) con sesenta páginas por número y cuatro ilustraciones, querían llegar a empresarios manufactureros y agrícolas, dueños de fábricas, ingenieros y al resto de la población que se interesase en la industria y la agricultura.

Portefeuille économique des machines, de l'outillage et du matériel tuvo periodicidad mensual, tenia entre 4 y 12 páginas además de entre 4 y 8 láminas. Según sus editores, la publicación respondía a la necesidad de dar a conocer las máquinas entre los técnicos. Se dirigía, pues, a ingenieros, mecánicos, constructores de máquinas, empresarios y estudiantes.

Hasta 1882 la revista estuvo dirigida por el ingeniero de puentes y caminos C.A. Oppermann. En ese año se creó un comité formado por diversos ingenieros ${ }^{3}$ que se hizo cargo de la dirección, mientras que de la gerencia se ocupaba el ingeniero civil de minas $\mathrm{CH}$. Béranger. A partir de 1889, Béranger asumió en solitario la dirección hasta el último número aparecido en 1914.
Revista de Obras Públicas, Fundada por un entusiasta grupo de Ingenieros de Caminos, en 1854 quedó integrada en la Escuela de Caminos, bajo cuya tutela permaneció hasta 1903, cuando se fundó la Asociación de Ingenieros de Caminos que será su editora hasta 1923. Como órgano profesional de los ingenieros de Caminos, Canales y Puertos, su línea de trabajos se enmarca dentro de la Ingeniería Civil, pero incorpora trabajos de otras ramas de la tecnología. Hoy es la publicación periódica técnica más antigua en España.

La Gaceta industrial económica y científica fue una revista que como indica en su portada estaba consagrada al fomento de la industria nacional. Surgía el 7 de enero de 1865 con unas ocho páginas ilustradas con gravados y periodicidad semanal. Entre 1869 y 1870 se redujo la periodicidad a cada diez días, con dieciséis páginas. Entre 1871 y 1876 se volvió a la periodicidad semanal y desde 1877 hasta 1890 pasó a ser quincenal. En 1890 se editó con un suplemento titulado Revista de la electricidad y en 1891 La Gaceta Industrial se fusionó con la revista Ciencia eléctrica que dirigía José Casas Barbosa pasando a denominarse Gaceta industrial y ciencia eléctrica.

De la dirección y edición de la Gaceta Industrial se encargó José Alcover Sallent (Vilafranca del Penedés 1835 - Madrid 1894), ingeniero industrial de la promoción de 1856 del Real Instituto Industrial de Madrid. Ingresó en el Cuerpo de Telégrafos donde diseñó y realizó algunos tendidos de líneas de conexión entre Catalunya y el resto de la península. ${ }^{4}$ En 1864 renunció a su puesto funcionarial y volvió a Madrid donde fundó esta revista y dirigió la empresa Centro General de la 
Industria dedicada a proporcionar máquinas y materiales para la industria, montar talleres, realizar ensayos públicos. La empresa contaba con una exposición permanente de máquinas, abierta al público. Alcover también publicó diversas monografías técnicas propias o de otros autores mediante fascículos incorporados en los sucesivos números de la revista. ${ }^{5}$ La idea que Alcover tenía sobre la revista la resumía en las primeras frases de uno de sus artículos:

Un periódico como la Gaceta industrial en algunas cuestiones tiene que hacer algo más que decir a sus lectores lo que ha pasado o lo que está pasando; y hasta cierto punto tiene que saber y decir lo que va a pasar (Gaceta Industrial 10-10-1881, p. 295).

Según David Petrel, que ha estudiado esta revista en cuanto a los discursos que contiene sobre la invención, las patentes y los avances tecnológicos, la Gaceta Industrial es un ejemplo de divulgación de las ventajas de la máquina y de difusión de la idea que el progreso tecnológico determinaba la riqueza de las naciones:

El discurso que encontramos en ella tiene dos grandes ejes, a saber, la retórica política de construcción de los Estados-nación y de implantación de un programa de modernización económica y la retórica positivista de apología del desarrollo tecnológico e industrial. La Gaceta Industrial, aunque de influencia política y social limitada, destacaba por su contenido eminentemente práctico y por facilitar la solicitud y la publicidad de los privilegios industriales, patentes de invención, marcas y modelos industriales concedidos en España y, en ocasiones, en el extranjero (Petrel, 2009, 65).

Annales industrielles era una revista quincenal y en un principio alternaba los números de manera que uno se dedicaba mayoritariamente a la industria y el siguiente a la ciencia. Se encuadernó en dos volúmenes anuales. Su objetivo era popularizar el progreso de la industria internacional. Desde 1869 la publicaba Frédureau, $\mathrm{H}$ de Chavannes et Cie., y la dirigió el ingeniero civil A. Cassagnes y desde 1892 la dirección pasó a $F$. Frédureau, otro ingeniero civil, y la publicó Frédureau et Cie.

El Porvenir de la Industria, con el subtítulo periódico semanal de ciencias, industria, agricultura y comercio, se editó con periodicidad semanal y fue fundado y dirigido durante sus primeros años por el ingeniero industrial Magín Lladós y Rius, al que sucedió el también ingeniero industrial Federico Cajal. Cabe destacar que fue premiado en la Exposición Universal de Filadelfia de 1876. Sus trabajos se exponían en varias secciones: Sección Doctrinal; Ciencias e Industria; Parte Oficial;
Miscelánea y Sección Comercial, añadiendo además una sección de Correspondencia y los Anuncios

Fue una publicación de interés, por la información propia que trabajaba y por la que extraía de otras publicaciones, tanto españolas, como extranjeras, y contiene trabajos muy interesantes relacionados con el gas y la electricidad, como ejemplo insertamos el precio del gas en distintas ciudades:

Tabla 3. Precio del gas en diferentes ciudades.

\begin{tabular}{|c|c|c|}
\hline población & $\begin{array}{c}\text { Alumbrado } \\
\text { particular } \\
\left(\text { pts./m }{ }^{3}\right)\end{array}$ & $\begin{array}{c}\text { Alumbrado } \\
\text { público }\left(\mathrm{pts} . / \mathrm{m}^{3}\right)\end{array}$ \\
\hline Ámsterdam & $0,20-0,21$ & $0,20-0,21$ \\
\hline Berlín & 0,20 & 0,20 \\
\hline Bruselas & 0,20 & 0,20 \\
\hline Barcelona & 0,21 & 0,21 \\
\hline Burdeos & 0,22 & 0,05 \\
\hline Amberes & 0,23 & 0,23 \\
\hline Lille & 0,25 & 0,20 \\
\hline Lyon & $0,25-0,30$ & 0,17 \\
\hline París & 0,30 & 0,15 \\
\hline Rouan & 0,32 & 0,17 \\
\hline Lieja & 0,32 & 0,25 \\
\hline Marsella & 0,33 & 0,20 \\
\hline Londres & $0,16-0,17$ & 0,20 \\
\hline Baltimore & 0,35 & 0,20 \\
\hline Nueva York & 0,40 & 0,20 \\
\hline Boston & 0,42 & 0,47 \\
\hline Viena & 0,53 & 0,20 \\
\hline San Francisco & 0,54 & 0,20 \\
\hline Chicago & 0,20 & 0,20 \\
\hline Nueva-Orleans & 0,20 & 0,20 \\
\hline
\end{tabular}

La Revista Tecnológico Industrial fue la publicación mensual de la Asociación de Ingenieros Industriales de Barcelona, entidad constituida en 1863 con once socios fundadores siendo su primer presidente Luis Justo y Villanueva. ${ }^{6}$ En marzo de 1878 se publicó el primer número como Boletín de la Asociación. En diciembre de 1877 fue elegido nuevo presidente Louis Rouvière en sustitución de Ramon de Manjarrés que, al dejar la presidencia, se hizo cargo de la comisión que había de sacar a la luz el Boletín. 
El Boletín Mensual de la Asociación de Ingenieros Industriales de Barcelona recogía los extractos de las sesiones de las Juntas General y Directiva y un apartado final titulado "Movimiento científico-industrial" con noticias de novedades tecnológicas destacables. Por ejemplo, en noviembre de 1878 se hablaba de "El alumbrado eléctrico" y las máquinas patentadas por Edison, o en setiembre de 1879, del "Gas de los pantanos en un buque" donde se daba cuenta de una explosión habida en un buque carbonero que se dirigía a Malta.

A partir de 1880 este boletín tomó el nombre de Revista Tecnológico-Industrial, cambiando su formato, estructurándose en secciones: "Sección técnica", "Parte oficial", y "Crónica de la Asociación". Compartimentación que quedó pronto corta y a partir de 1883 desapareció la sección técnica y su lugar lo ocuparon tres secciones: "Tecnología", "Ferrocarriles" y "Ciencias y sus aplicaciones". Desde 1887 desaparecieron las secciones y el sumario de cada número solo mostraba los títulos de los artículos y las noticias y la bibliografía. Así se fue publicando hasta 1918 en que cambió de nombre pasándose a llamar Técnica. Revista Tecnológico-Industrial con ese nombre y un nuevo formato se publicó hasta 1936.

Industria e Invenciones fue una revista que se anunciaba como dedicada al estudio de las ciencias, las artes, la legislación, el comercio en sus relaciones con la industria. Apareció semanalmente desde 1884 a 1921 con ocho o diez páginas ilustradas. Al incluir anuncios podía tener hasta unas veinticuatro páginas. Tomó el relevo y los compromisos adquiridos con los subscriptores de la revista Gaceta de la Industria y de las invenciones dirigida por Ventura Serra y Crusells ${ }^{7}$ entre 1881 y 1882, que tras su fallecimiento dejó de publicarse. Por ello Industria e Invenciones se obligaba a publicar los inventos, adelantos, mejoras y descubrimientos científicos ocurridos no solo en España sino en el extranjero. También se comprometía a publicar una relación clasificada de las patentes concedidas y caducadas, así como las marcas otorgadas por la Oficina española de patentes.

Fue dirigida por el ingeniero industrial Gerónimo Bolíbar de la promoción de 1875 de la Escuela de Barcelona. Gerónimo Bolíbar Gallup había nacido en 1852 en Bueu (Galicia), Su familia eran pescadores catalanes procedentes de Calella que se habían establecido en Galicia para ocuparse de la explotación y fabricación de la pesca en fábricas de salazón. Esta familia y otras similares eran conocidas como "os fomentadores". ${ }^{8}$ Gerónimo Bolíbar desarrolló su vida profesional y familiar en Barcelona, donde ejerció como agente de la propiedad industrial en una oficina propia, compaginando con la edición de la revista.

\section{METODOLOGÍA Y RESULTADOS}

De la consulta de las revistas se ha extraído todo lo relativo a gas y electricidad para poder comparar entre si sus fuentes de información, sus afinidades con uno u otro tema y para analizar finalmente que clase de informaciones relevantes contienen. Los parámetros que nos han interesado inicialmente han sido: el número de temas tratados por año y los cambios de tendencia con el paso de los años.

Tabla 4. Valor medio de los temas tratados por año.

\begin{tabular}{|c|c|c|c|c|c|}
\hline Publicación & $\begin{array}{c}\text { Años (hasta } \\
\text { 1910) }\end{array}$ & Tema gas & $\begin{array}{c}\text { Tema } \\
\text { electricidad }\end{array}$ & $\begin{array}{c}\text { Tema } \\
\text { gas/año }\end{array}$ & $\begin{array}{c}\text { Tema } \\
\text { electricidad/año }\end{array}$ \\
\hline Le Génie Industriel & 20 & 156 & 44 & 8 & 2 \\
\hline Portefeuille Economique des Machines & 55 & 170 & 220 & 3 & 4 \\
\hline Revista de Obras Públicas & 54 & 63 & 189 & 1 & 4 \\
\hline Gaceta Industrial, Económica y Científica & 27 & 279 & 526 & 10 & 19 \\
\hline Annales Industrielles & 26 & 217 & 771 & 8 & 30 \\
\hline El Porvenir de la Industria & 24 & 63 & 265 & 3 & 11 \\
\hline Revista Tecnológico Industrial & 33 & 55 & 262 & 2 & 8 \\
\hline Industria e Invenciones & 27 & 194 & 1150 & 7 & 43 \\
\hline
\end{tabular}


En los 20 años en que Le Génie Industriel fue publicado, el número de artículos de gas siempre fue superior al de electricidad, véase la tabla 4 y la gráfica 1.

En el Portefeuille économique des machines, con su predisposición a las máquinas, más que otros temas generales o teóricos, la evolución de las referencias aparecidas parece más equilibrada que en las otras revistas (gráfica 2). Aunque el gas se mantiene con una cierta regularidad con algunos altibajos, con la entrada del siglo XX decae considerablemente, mientras que la electricidad destaca con algunos picos, el más importante entre 1878 y 1884.

En la Revista de Obras Públicas, pese a su enfoque hacia los temas constructivos, el gas y la electricidad fueron residuales, excepto en los años 1897 a 1899, en que la electricidad se convirtió en un tema destacado por la difusión de las subastas para alumbrado público que se efectuaron en aquellos años en las distintas ciudades españolas (gráfica 3).

En la Gaceta Industrial, se pone de manifiesto que, hasta 1878, el número de referencias de gas estuvieron ligeramente por encima de la electricidad, y a partir de ese año empezó un despegue de la electricidad alcanzando máximos a principio de 1880 y se mantuvo por encima del gas hasta final de la publicación (grafica 4).
En los 26 años que se publicaron Annales Industrielles, los artículos y noticias de gas y de electricidad fueron variando. Hasta 1876 el gas superaba la electricidad y a partir de ese año el cambio fue radical. Las referencias al gas se mantenían o se reducían, mientras que la electricidad iniciaba un proceso de ascensión, que a partir de 1881 fue creciendo rápidamente. Esto coincidía con la aparición desde el segundo volumen de 1880 de una sección dedicada al alumbrado eléctrico y en el primer volumen de 1883 de otro apartado destinado a la electricidad (gráfica 5).

En El Porvenir de la Industria, la electricidad supera siempre con creces al gas en las referencias de artículos (gráfica 6).

Desde su inicio en 1878 hasta 1910 la Revista Tecnológico Industrial publicó diversos artículos sobre gas y electricidad cuya evolución temporal queda reflejada (gráfica 7).

Industria e Invenciones, nacida en una época en que la electricidad ya estaba en constante evolución, es lógico que su interés por esta industria fuera mayor que por al gas, como queda patente en la evolución cuantitativa en los cincuenta y cuatro volúmenes aparecidos en veintiséis años. Además de tener un apartado denominado Revista de Electricidad (gráfica 8).

Gráfica 1. (Elaboración propia).

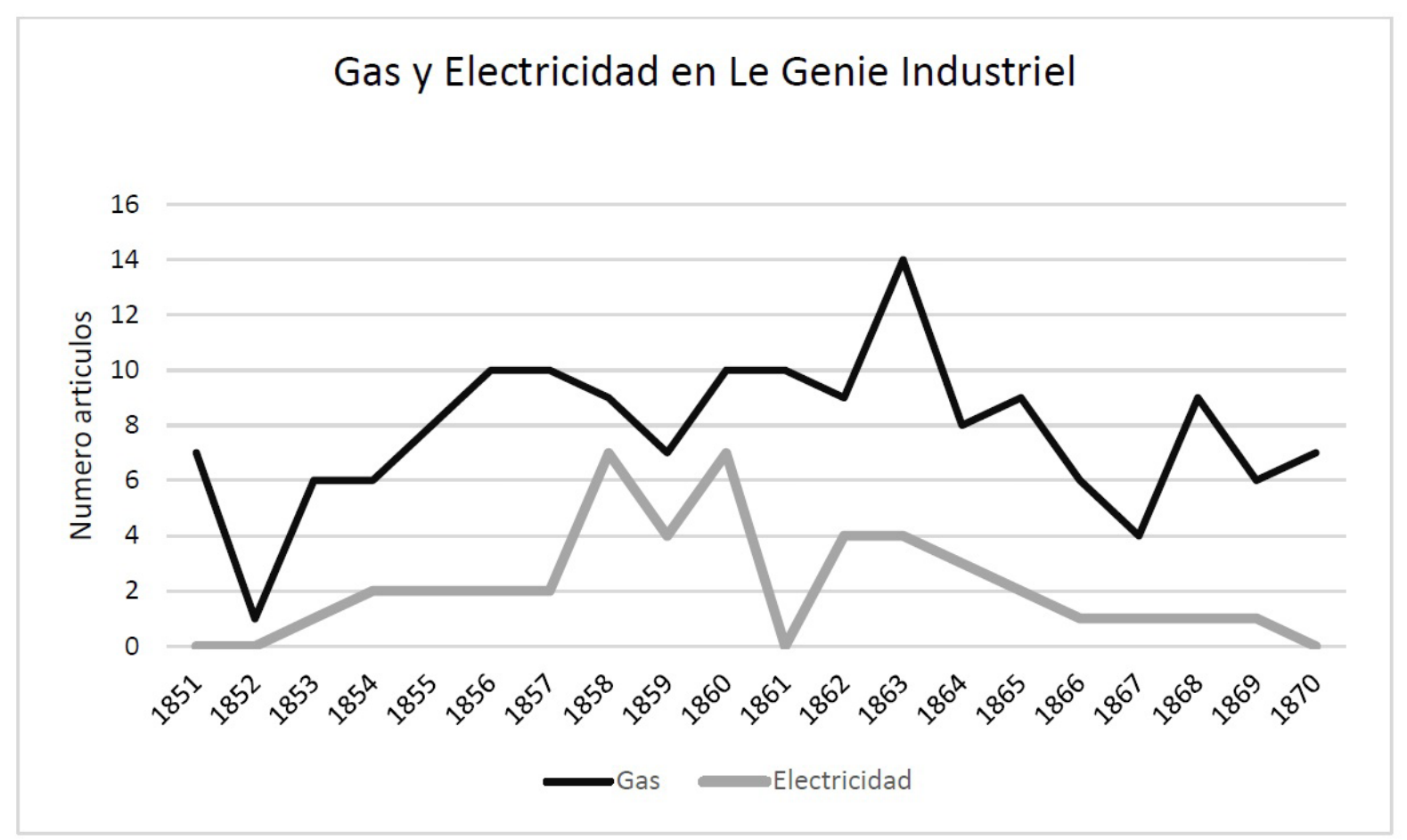


Gráfica 2. (Elaboración propia).

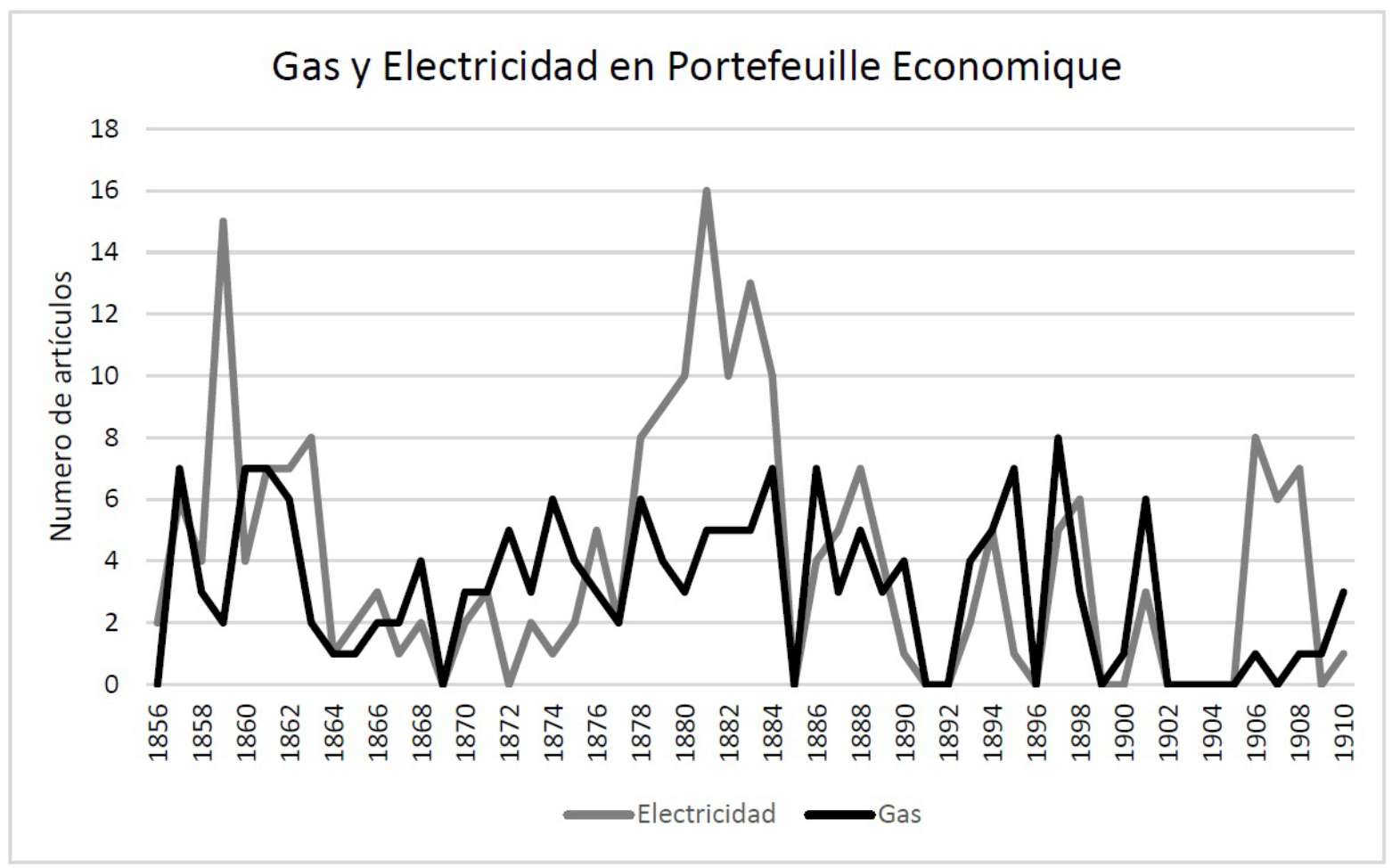

Gráfica 3. (Elaboración propia).

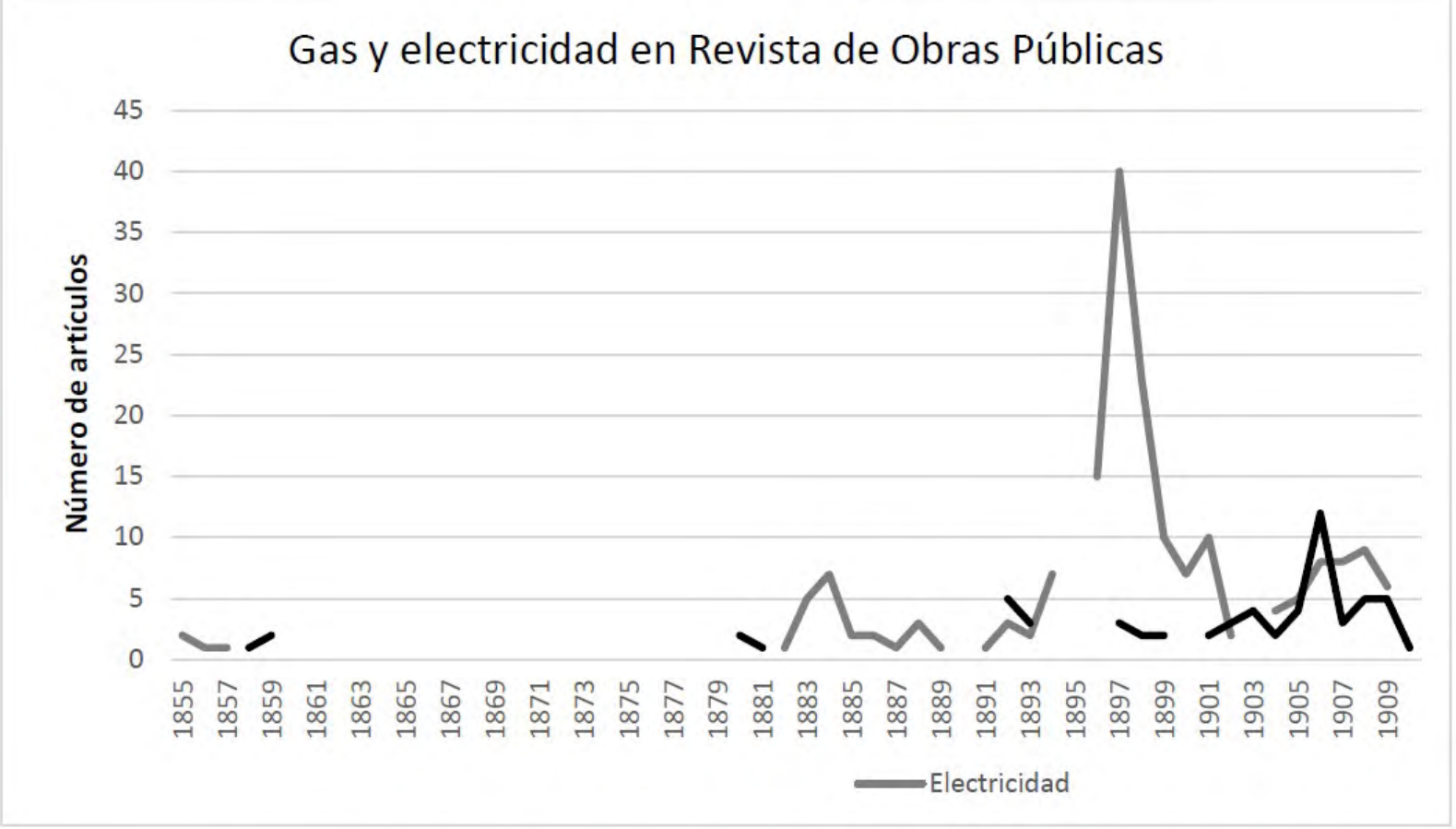


Gráfica 4. (Elaboración propia).

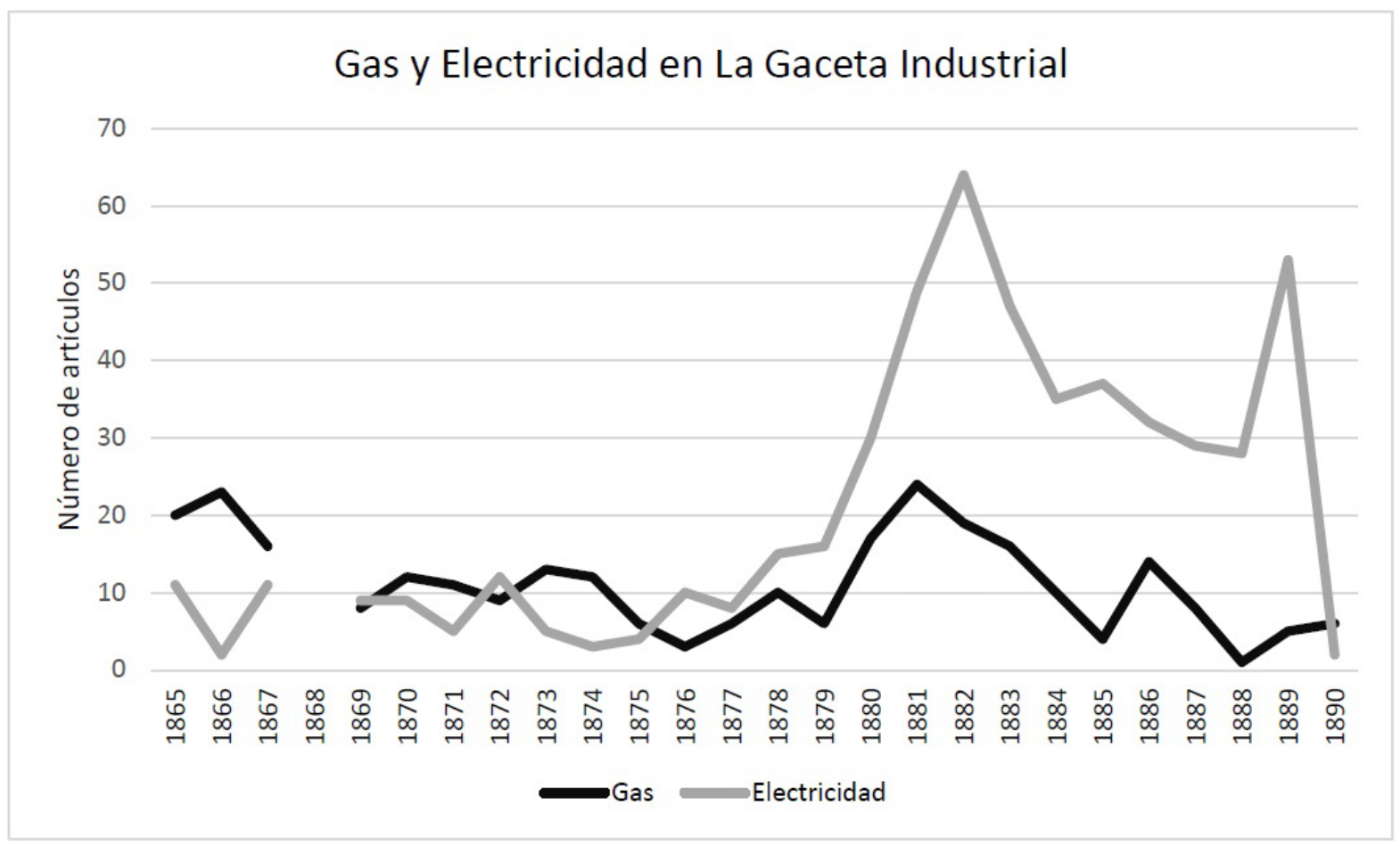

Gráfica 5. (Elaboración propia).

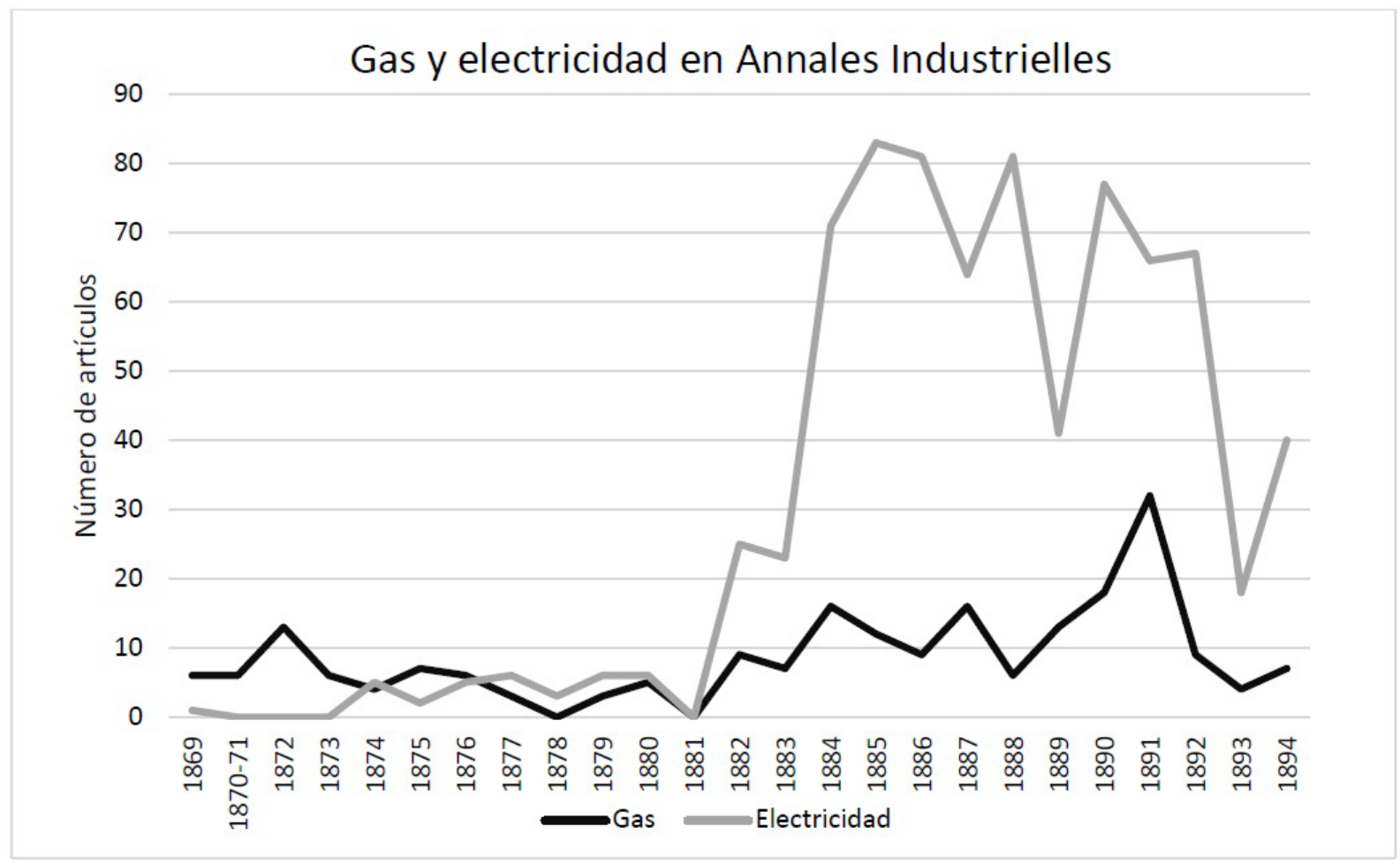


Gráfica 6. (Elaboración propia).

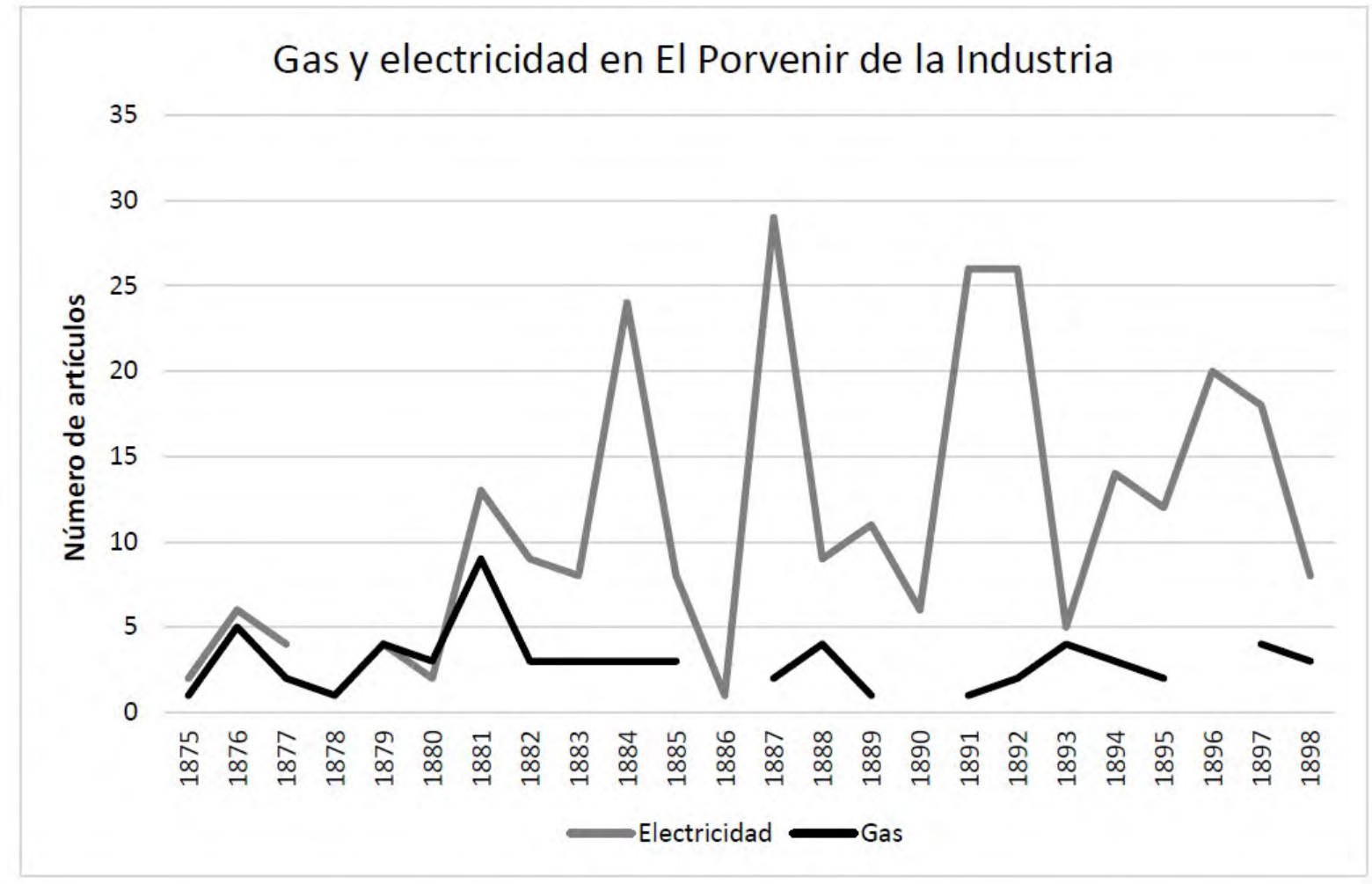

Gráfica 7. (Elaboración propia).

Gas y Electricidad en la Revista Tecnologico Industrial

30

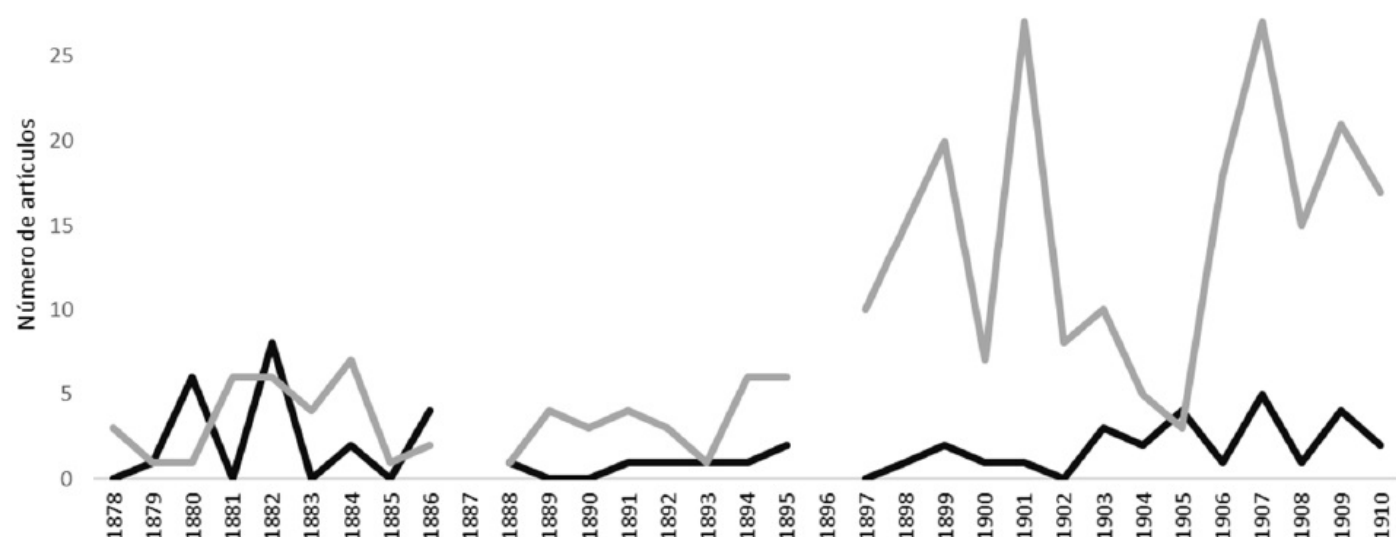

Gas Electricidad 
Gráfica 8. (Elaboración propia).

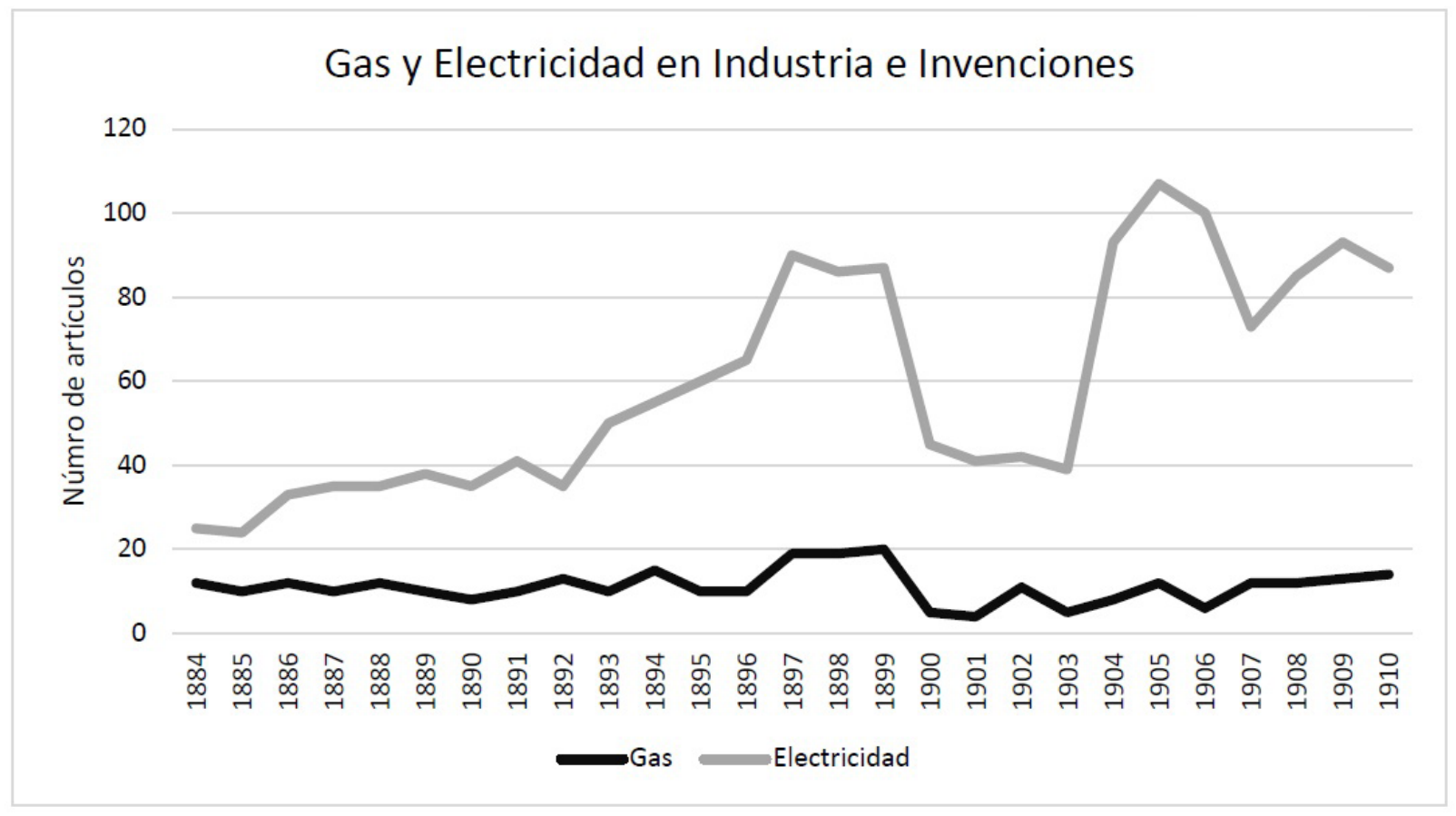

Como se ha indicado, las distintas publicaciones tienen su origen y final, tal como se muestra en la tabla 5 , lo que imposibilita un análisis espacial uniforme, no obstante, con la homogeneidad de la metodología escogida, la agrupación de todas los artículos nos permite afirmar lo que ya aparecía en cada una de las revistas, la electricidad se impone en el relato de noticias, informaciones y estudios que aparecen a partir de 1879 , que es cuando la aparición de las máquinas Gramme, Siemens, las lámparas Edison o Swan, ponen a la electricidad a la cabeza de la industria, y como consecuencia a la cabeza en su difusión (Grafica 9). Esperable, lo era, pero con este análisis se han puesto las cifras de una realidad, y no solo ello, sino que se han detectado una serie de temas, tratados en cada una de las revistas, que son muy importantes, no solo para conocer las distintas fuentes de referencia, sino para poder profundizar en el desarrollo de la transferencia de tecnología en España.

Tabla 5. Origen y final de las publicaciones.

\begin{tabular}{|c|c|c|c|c|c|c|c|c|c|c|c|c|c|}
\hline Revista & 1850 & 1855 & 1860 & 1865 & 1870 & 1875 & 1880 & 1885 & 1890 & 1895 & 1900 & 1905 & 1910 \\
\hline \multicolumn{14}{|l|}{ Le Genie Industriel } \\
\hline \multicolumn{14}{|l|}{ Le Portefeuille Economique .. } \\
\hline \multicolumn{14}{|l|}{ Revista de Obras Publicas } \\
\hline \multicolumn{14}{|l|}{ La Gaceta Industrial ....... } \\
\hline \multicolumn{14}{|l|}{ Annales Industrielles ... } \\
\hline \multicolumn{14}{|l|}{ El Porvenir de la Industria } \\
\hline \multicolumn{14}{|l|}{ Revista Tecnológico-Industrial } \\
\hline Industria e Invenciones & & & & & & & & & & & & & \\
\hline
\end{tabular}


Gráfica 7. (Elaboración propia).

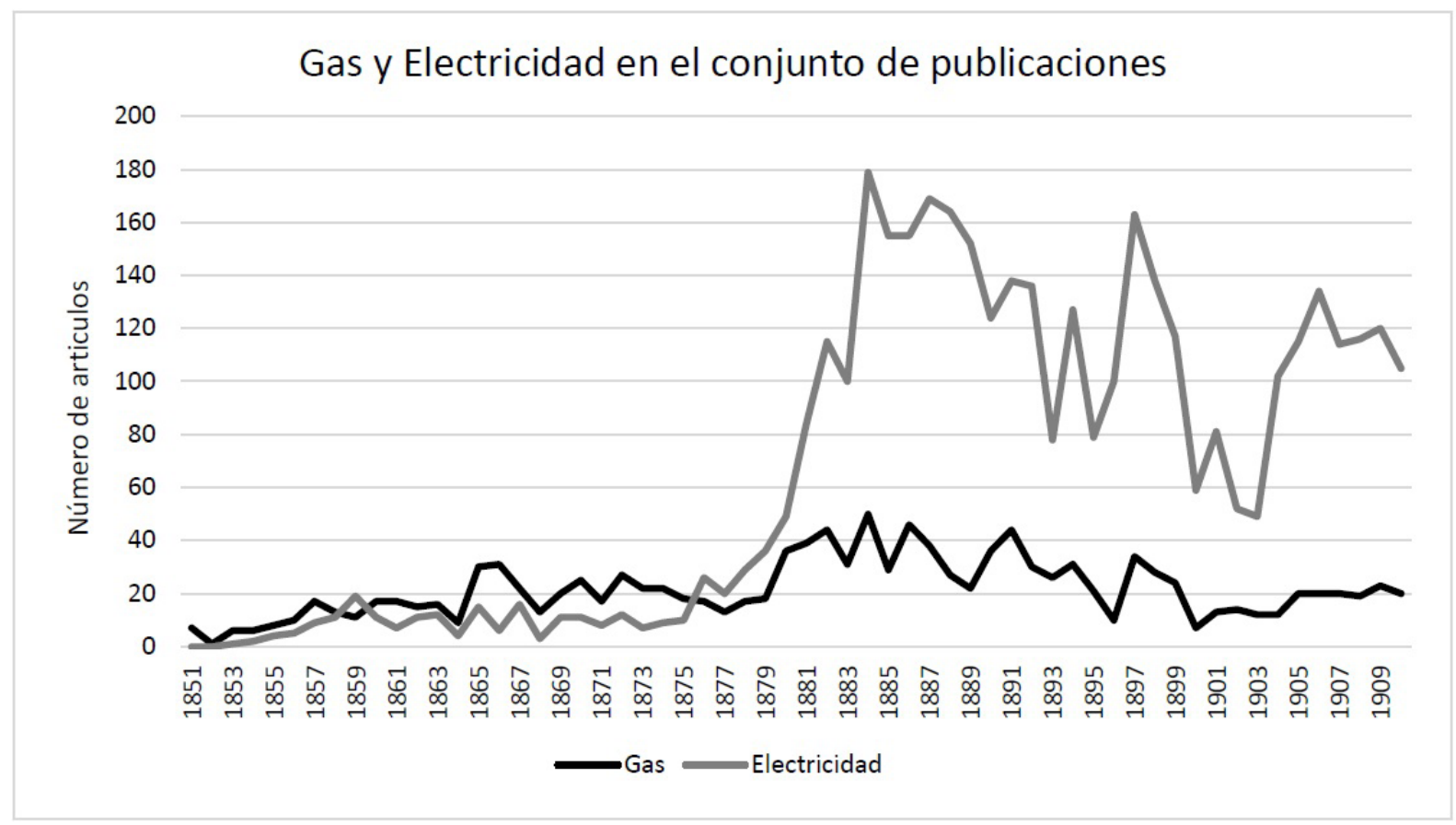

\section{DOS ASPECTOS QUE DESTACAMOS DEL ANÁLISIS DE CONTENIDOS}

\subsection{PROCEDIMIENTOS ALTERNATIVOS DE PRODUCCIÓN DE GAS}

En el periodo estudiado el sistema de producción de gas de hulla ya estaba establecido y aunque se podía mejorar, como así fue, presentaba unos condicionantes que forzaban la búsqueda de otros procedimientos alternativos. El gas de hulla era caro como consecuencia del precio de la hulla, la mayor parte y la mejor procedía de la Gran Bretaña. Solo las fábricas grandes eran rentables y en consecuencia este gas no se adecuaba a instalaciones pequeñas o aisladas. Por ello se buscó maneras de conseguir gas a partir de otros productos como el sebo, la leña, el corcho, el aceite o el petróleo. Así fue como surgieron las tecnologías de fabricación de gas de leña, gas de aceite, gas de agua (Alayo y Barca, 2011, p.125-139) y también el gas de acetileno.

Le Génie Industriel en el primer número presentaba como novedad la fabricación de gas a partir de agua de jabón. El sistema consistía en aprovechar la grasa contenida en el agua del lavado de la lana, la cual mezclada con cal viva daba como resultado una pasta que una vez seca se introducía en la retorta. El proceso se estaba aplicando en una fábrica de gas de Mulhouse con buenos resultados (Génie Industriel, 1851, l, p. 68).
Unos años después en un nuevo artículo, extraído del Journal de l'Éclairage au gaz, se describía el proceso con mayor detalle (Housseau, 1886, p.190).

La aplicación de este gas en Francia tuvo su repercusión en poblaciones catalanas como Figueras donde se aplicó mediante por la Sociedad Humbert y Cía., que había obtenido una patente en España en 1858. ${ }^{9}$ Dos décadas después, en 1884, Industria e Invenciones daba la noticia de un invento realizado en Australia de un aparato que usaba el sebo destilado en una retorta para producir gas (Industria e Invenciones, 15-03-1884, p.107).

Obtener gas de la destilación de la leña no era algo nuevo, había sido uno de los primeros ensayos realizados en Francia a principios del siglo XIX por Philippe Lebon. Sin embargo, no tuvo demasiada difusión hasta algunos perfeccionamientos posteriores como el que llevó a cabo el Dr. Pettenkofer y que recoge Le Génie Industriel (Pettenkofer, 1855, p.258-259).

En 1875 la Gaceta Industrial daba la noticia que en la población francesa de Nérac se fabricaba gas a partir de las virutas y residuos de corcho destilados en un recipiente cerrado (Gaceta Industrial, 1875, p. 207) Unos años después, otra noticia atribuía el mérito de ese invento a Auguste Combé d'Alma y daba cuenta de la presentación del alumbrado por corcho establecido 
en el Teatro de la Gran Opera de París. El autor de esta nota defendía su aplicación en poblaciones de 10.000 a 20.000 habitantes. Consideraba que era: "posible, como decimos, establecer en España 30 o 40 fábricas de gas de corcho que fuera excelente negocio" (Gaceta Industrial, 25-11-1880, p.342-343). La defensa de este nuevo tipo de gas hizo reaccionar de manera contundente a Ramon de Manjarrés y Bofarull, director de la Escuela de Ingenieros industriales de Barcelona. Explicaba que había tenido la oportunidad de asistir a las primeras pruebas, que se habían realizado en la Opera de París y afirmaba que el uso del corcho no era una novedad ya que, en las escuelas de la Junta de Comercio en la Lonja de Mar de Barcelona, José Roura y Estrada ya lo había utilizado. Cuenta que inicialmente Roura había destilado aceite de pescado que era barato pero que posteriormente, "en 1840 las clases de dibujo y otras que se daban de noche en aquel establecimiento viéronse (sic) alumbradas por gas de corcho" (Manjarres, 1880, p 371). Roura, que era natural de Sant Feliu de Guíxols en donde se explotaba el corcho a gran escala en la fabricación de tapones, consiguió la autorización de la Junta de Comercio para substituir el aceite de pescado por los desperdicios del corcho. Este alumbrado estuvo en funcionamiento hasta que las escuelas se constituyeron en Escuela Industrial y en Barcelona se había ya establecido un alumbrado público por gas de hulla. Manjarrés, que afirmaba haber mencionado la producción de gas de corcho en 1860 en sus clases de química en la Escuela Industrial de Sevilla, también citaba el Curso de Química Industrial (Barcelona, 1851) de Pedro Roqué Pagani en cuya obra se explicaba la fabricación de este gas hecha por Roura. Finalmente, justificaba el uso del corcho en años anteriores, pero se oponía a su aplicación en ese momento ya que el corcho era más útil y mejor aprovechado en otras cuestiones.

No solo el corcho, otros residuos de la madera como el serrín o las virutas también fueron objeto de noticias en la Gaceta Industrial. Dos de ellas nos hablan del Canadá, donde se habían establecido fábricas de gas que aprovechaban el serrín en la ciudad de Deseronto en Ontario destilándolo en calderas verticales (Gaceta Industrial, 10-11-1886, p. 330). Un artículo que la Gaceta Industrial extrajo del Boletín de la Cámara de Comercio de Nueva York se hacía eco del invento de José F. Toraya, español nacido en Cuba, para producir gases a partir del serrín y las virutas (Gaceta Industrial, 10-04-1889, p.100).

Finalmente, daremos algunos detalles del uso del acetileno que tuvo importancia en algunas poblaciones pequeñas en España. En 1895 la Revista Tecnológico Industrial incluía un artículo (traducción de otro del Journal de l'éclairage au gaz) sobre la producción y las aplicaciones del acetileno en el alumbrado (Revista

Figura 2. Gasógeno para fabricar gas acetileno patentado por Bosque (Izquierda). Lámpara de gas acetileno patentado por Bosque (derecha). Industria e Invenciones, (3-12-1898), pp. 210-211.
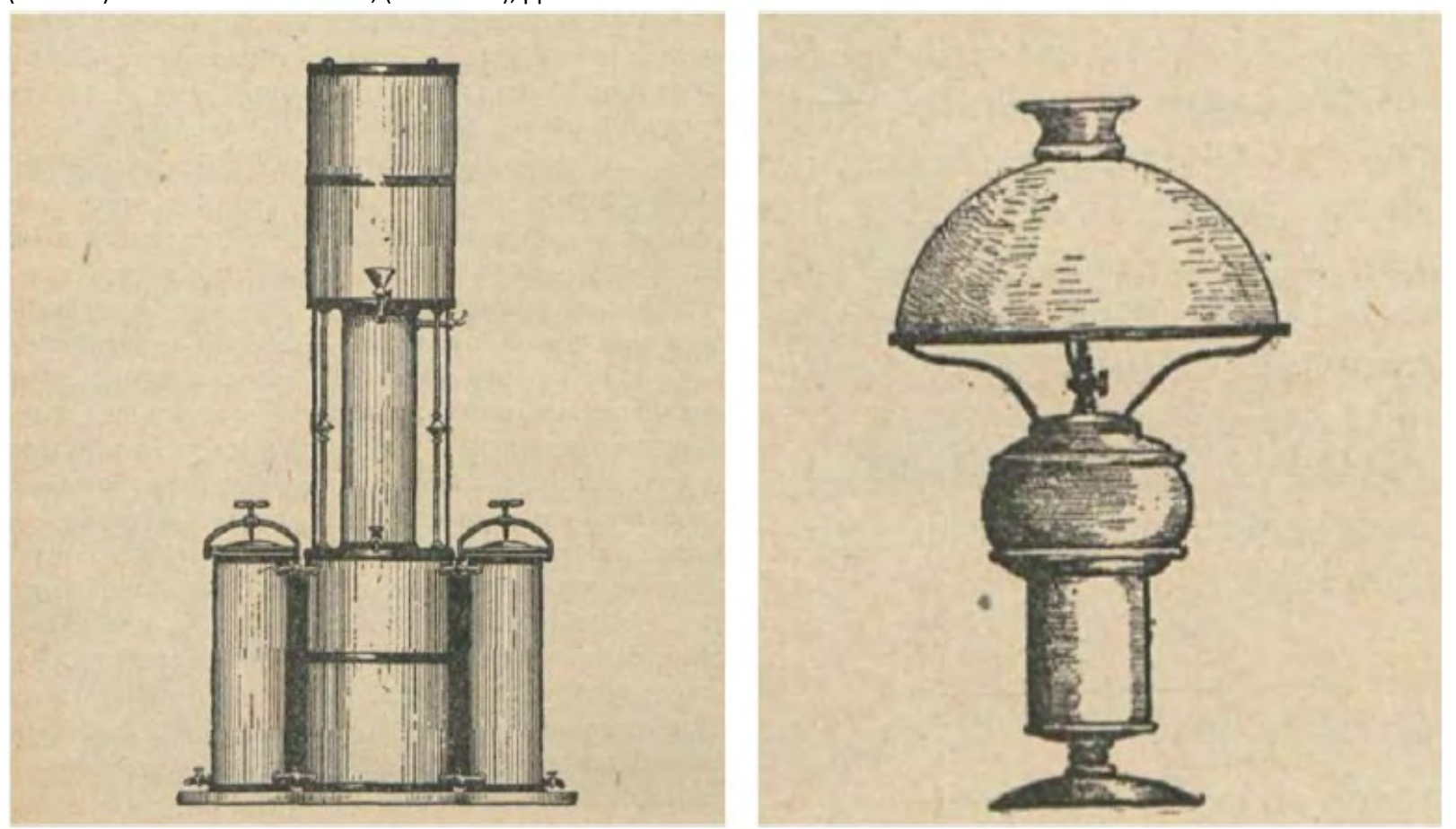
Tecnológico Industrial, abril, p. 114-122, mayo, p.143145.). El acetileno o etino es un gas incoloro, de olor a ajos, toxico, que arde dando la llama fuliginosa. Se fabrica partir del carburo de calcio al ponerlo en contacto con el agua y quemado en mecheros da una luz superior a los otros gases, aunque también se puede usar para enriquecer la potencia lumínica del gas de hulla.

Nuevamente el acetileno fue el centro de un artículo en la misma revista. En este caso el autor era Bernardo Puig ${ }^{10}$ y en él se describía un gasógeno para fabricar acetileno similar a los usados en el alumbrado de vagones de tren (Puig, 1903, p. 119-130).

También Industria e Invenciones dedicó un buen número de noticias y artículos al acetileno. En enero de 1897 se describía un aparato, patentado ${ }^{11}$ en España por el belga Gastón Ragot (Industria e Invenciones, 2-01-1897, p.5.). Al mes siguiente, un extenso artículo repartido en tres números consecutivos hablaba de las propiedades de este gas y de sus aplicaciones (Industria e Invenciones, 6-02-1897, p. 47; 13-02-1897, p. $60 ; 20-02-1897$, p. 68). Fue habitual desde entonces la aparición de noticias sobre su uso en boyas, ferrocarriles o tranvías ${ }^{12}$

La difusión que el acetileno había conseguido dio como resultado en 1898 la constitución en Barcelona de la Sociedad franco-española del acetileno para fabricar este gas a partir del carburo de calcio y para vender aparatos de su uso en alumbrado (Industria $e$ Invenciones, 2-04-1898, p.132). Esta sociedad, que estaba bajo la influencia su homóloga del país vecino, la dirigía, Enrique Alexandre Gracián, ingeniero de minas francés residente en la ciudad condal y autor de algunas patentes sobre la fabricación de acetileno y de una lámpara de gas. ${ }^{13}$ No era esta la única empresa que comercializaba lámparas y gasógenos para el acetileno. Carlos y José María Bosque fabricaban un extenso sur-

Figura 3. Gasógenos inventados por Ponces. Industria e Invenciones, (29-12-1900), pp.214-218.

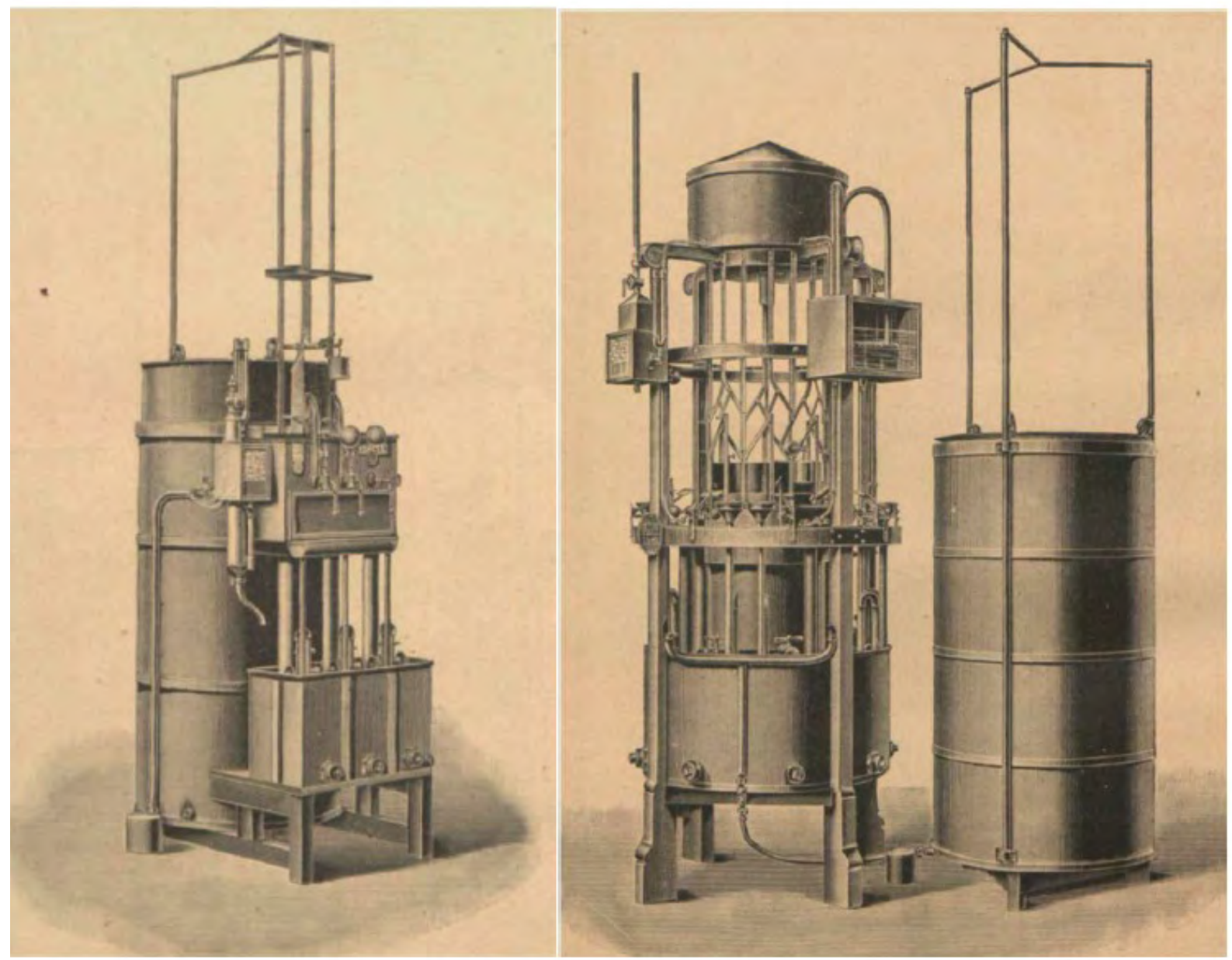


tido de lámparas y gasógenos que habían patentado (Industria e Invenciones, 3-12-1898, p. 210-211). ${ }^{14}$

En 1898 tuvo lugar en el Imperial Institute de Londres una exposición de aparatos de acetileno y el año siguiente otra en Budapest con motivo de la celebración del segundo Congreso Internacional de acetileno que fueron promocionados por respectivas noticias aparecidas en Industria e Invenciones. ${ }^{15}$

Acabaremos con unos artículos que dan detalles de algunos inventos sobre el acetileno. En 1899 se informaba y describía el aparato patentado por el barcelonés Inocencio Ortiz Alza (Industria e Invenciones, 24-06-1899, p. 239-240). ${ }^{16}$ En 1900 se daba cuenta de otros aparatos productores de acetileno que fabricaba la empresa Costa y Ponces S. C., apropiados para alumbrado de poblaciones (Industria e Invenciones, 29-121900, pp.214-218). ${ }^{17}$

La empresa Costa y Ponces empezó iluminando fábricas como las de Moratonas y Molins y la de J. Gorina e hijos en Sabadell y la Comas y Nebots en Barcelona y otras más situadas en Sant Quintí de Mediona, Manresa, Badalona y Sant Quirze de Besora. Posteriormente tras ampliar su capital, convertirse en sociedad anónima (Compañía General del Alumbrado por Acetileno S.A.) y ser gestionada por los grandes nombres de la industria catalana, aplicó el acetileno al alumbrado de diversos municipios de Catalunya como Piera, Palamós, Cassà de la Selva, Llagostera, Olesa, Vallmoll, Gandesa, Mora d'Ebre, Torredembarra ${ }^{18}$ y Cervera ${ }^{19}$. También en Ciutadella en Menorca y Aljarque en Huelva. Así como en algunas estaciones de la Compañía de ferrocarriles MZA (Madrid, Zaragoza, Alicante) (Cabana, 2001, 349354). Lo que pone de manifiesto el alcance que había tomado a principios del siglo el acetileno en el alumbrado de poblaciones pequeñas.

Finalmente, Industria e Invenciones da cuenta en 1901 de otro aparato productor de acetileno de unos inventores tarraconenses, Juan Danús y José Mallol, que habían patentado ${ }^{20}$ unas mejoras en el aparato productor de acetileno consistente en aislar el gasógeno del gasómetro (Industria e Invenciones, 17-081901, p.56).

\subsection{Del AUGE DE LA ELECTRICIDAD}

El físico francés Alexandre-Edmond Becquerel (1820-1891), escribía en la Revista de Obras Públicas:

Los reguladores de la luz eléctrica, que se construyen en la actualidad, funcionan con la suficiente precisión para que sea posible utilizarlos en aquellos casos en que pueda producirse la electricidad con las condiciones de constancia y economía convenientes.

$Y$ es que en aquel momento las pilas eran casi las únicas fuentes de electricidad y para iluminar espacios la electricidad resultaba como cuatro veces más cara que el coste del gas de la ciudad de París $(0,15$ fran$\cos / \mathrm{m}^{3}$ ). Además expresaba que el arco voltaico daba una luz brillante y concentrada, con muchas sombras, distinta de la luz de gas del alumbrado público que era más tenue y difusa con menores sombras, lo que en aquel momento se consideraba preferible, aunque el arco voltaico, opinaba:

se podía utilizar con ventaja para el de las construcciones que hayan de ejecutarse por la noche, o debajo del agua, quizá sería ventajoso recurrir a ella para el de las galerías de las minas, para hacer señales a bordo, para la iluminación de los faros, [...]. ${ }^{21}$

En aquel momento la electricidad ya era una tecnología conocida, pero la producción de electricidad con pilas era cara y las máquinas aún no habían evolucionado suficientemente, sin embargo el 8 de diciembre de 1858 se iluminaba con luz eléctrica uno de los dos faros gemelos situados en South Foreland (Gran Bretaña), la máquina eléctrica utilizada era una nueva versión de la que Holmes había fabricado en 1857 y la luz de arco era una lámpara Duboscq, fabricada en París, y tenía la propiedad que los contactos de carbón se mantenían aproximadamente con la misma separación para dar una luz de arco siempre igual. Era una de las primeras aplicaciones de la electricidad mediante máquinas eléctricas, que como apuntaba Becquerel producían electricidad con regularidad y en condiciones económicas.

Sin embargo 25 años después de estas opiniones que señalaban una progresión de la electricidad, y después de haberse celebrado la Exposición de Electricidad de 1881 en París, los gasistas no veían un desarroIlo fácil a la electricidad.

¿Qué ha sido de las promesas de los electricistas, que ofrecían reemplazar inmediatamente el gas en todas partes, en la vía pública, en el interior de los edificios y de las casas particulares? Exceptuando los ensayos no muy felices de alumbrado eléctrico de la plaza del Carrousel y las experiencias llevadas a cabo en la Opera para aplicar las lámparas Soleil a la iluminación de la escena, ien vano sería buscar las maravillosas aplicaciones con tanta insistencia anunciadas!

Ciertamente que, en aquel momento, la capacidad de distribución del gas era superior a la electricidad, 
las fábricas de gas se encontraban normalmente fuera de la ciudad y sus canalizaciones penetraban en la misma y la presión se mantenía a grandes distancias, mayores que las que podía abarcar la electricidad con su sistema de distribución, que en aquel momento era el concebido por Edison, con corriente continua y dos conductores: "Sin embargo, tal vez les queda a los electricistas un medio de arreglarlo todo, [...] consiste en apelar al gas para producir la electricidad". ${ }^{22}$

El gas como energía primaria para obtener electricidad y facilitar la iluminación eléctrica, esta era la apuesta que se planteaba en aquellos años, por la cierta dificultad de obtener una distribución eléctrica eficaz. Muchas pequeñas centrales eléctricas con motores de gas acoplados a generadores eléctricos, utilizando las ventajas de la distribución de gas, las de los pequeños motores de gas y las ventajas de la iluminación eléctrica. ¡Una idea excelente, planteada por los empresarios y defensores del gas!

Unos años después, las experiencias efectuadas con el llamado generador secundario de Gaulard \& Gibbs, permitían superar los obstáculos de la distancia de transmisión de la electricidad, con el uso de la corriente alterna en lugar de la corriente continua:
La dinamo estaba colocada en el taller y las lámparas a cinco kilómetros de los generadores; [...] La potencia en los extremos de los conductores principales, a cinco kilómetros era de 100 volts, lo que representa una pérdida de 10 por $100 .{ }^{23}$

Pese a que, tanto en Berlín, como en Barcelona, Madrid o Sevilla, el desarrollo de la red eléctrica se había iniciado entre 1881 y 1883, y la corriente continua era la utilizada, sin necesidad de acudir a lo que especulaban los gasistas de París mediante motores de gas, el progreso de la electricidad quedó reflejado en innumerables artículos, como los que hemos expuesto, y se fue adquiriendo la convicción de que la electricidad tenía su propio desarrollo.

\section{CONCLUSIÓN}

El estudio de ocho revistas técnicas españolas y francesas ha permitido conocer, el alcance del interés en la literatura industrial sobre dos temas: el gas y la electricidad, en un período que abarca entre 1850 y 1910, en que la electricidad releva al gas en el alumbrado, analizando más de 4.500 artículos de ambos temas.

Figura 4. Estación central de electricidad de South Kensington (Londres). El Porvenir de la Industria, 2-6-1889, p.718.

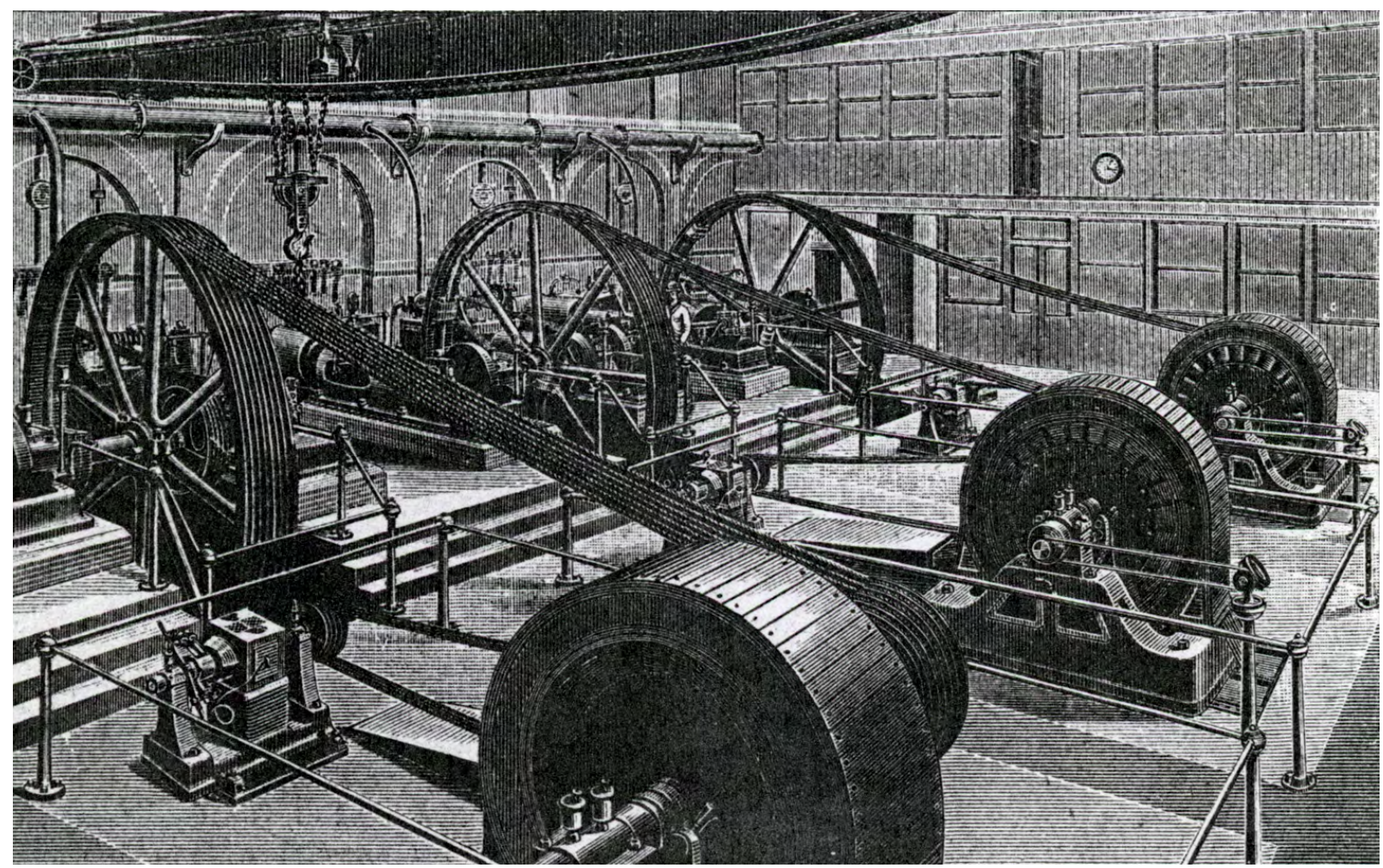


Tabla 6. Gas y electricidad en los extremos de la serie analizada.

\begin{tabular}{|c|c|c|}
\hline Publicación & año & Artículo \\
\hline Portefeuille ..... & 1856 & Amelioration de l'éclairage électrique applicable aux chantier et a l'industrie \\
\hline Revista de Obras Publicas & 1857 & Nota sobre el alumbrado eléctrico \\
\hline Revista de Obras Publicas & 1910 & Contador de gas con registrador eléctrico, sistema Thomas \\
\hline Industria e Invenciones & 1910 & Las modernas fábricas de gas \\
\hline
\end{tabular}

Este análisis, cuyo alcance no hemos agotado, pone de relieve temas de interés relacionados con la tecnología de ambas fuentes de energía. P. ej. que el elevado precio del carbón y los efectos de escala hicieron inviable la hulla en el alumbrado de poblaciones pequeñas, teniendo que recurrir a otras alternativas, como el acetileno. En cuanto a la electricidad, su uso no estuvo exento de rechazos, con puntos débiles que fueron superándose.

Los artículos de las publicaciones reflejan los avances realizados en cada tema, e ilustran el amplio campo de referencias que hemos encontrado en este estudio, que, expuesto aquí cuantitativamente, proseguimos analizando, no sin antes indicar que tanto gas como electricidad estuvieron presentes en todo el período,

\section{NOTAS}

1 Aquí sin duda se refería a Argand.

2 "La verbena de San Juan", El Museo Universal (30 de junio de 1857).

3 Se trataba de $\mathrm{CH}$. Baudry, ingeniero de construcciones navales y de ferrocarriles, A. Brull, politécnico, Chemin, ingeniero de puentes y caminos, Debize, ingeniero jefe de manufacturas del Estado, Aug. Doumerg, ingeniero civil, Pontzen, ingeniero civil.

4 Para completar la biografía de José Alcover se pueden consultar (Baltà, 2020, pp. 35-45), (Cano, s/f) (Portela, s/f)

5 Monografías Industriales. Motores empleados en la industria. Madrid 1871 publicado en el tomo 7 de la Gaceta Industrial. La maquinaria moderna. Motores, máquinas de vapor, de gas $y$ de aire caliente. Madrid 1882. En el tomo 9 publicó dos monografías del ingeniero Francisco Balaguer Primo (18411880), tituladas Fabricas de jabones y Riesgos por norias, bombas $u$ otras máquinas. En el tomo 10, Colores derivados de la anilina de José Vallhonesta Vendrell (1835-1899).

6 Las dos monografías que explican la historia de la esta institución son (Castillo, 1963) (Riera, 1988).

7 Ventura Serra era ingeniero industrial de la promoción de 1868 y murió en 1882 a edad muy prematura. (Alcover, 1882 , p. 129).

8 Gerónimo Bolíbar era el cuarto hijo del matrimonio de Santiago Bolíbar Bonell y Teresa Gallup contraído en Barcelona en 1840. Los descendientes de su hermano mayor Tomas fueron los propietarios de la empresa de conservas de pescado Massó Hermanos de la ría de Aldán. (Almirall, 2011).

9 Patente no 1690 de 8-02-1858 Archivo Histórico de la Oficina bastando como muestra lo que se expone en la tabla 6 , con artículos de electricidad presentes ya en los años 1856 y 1857 y artículos sobre gas presentes aún en el año 1910, que demuestra, más que de forma cuantitativa, el interés por ambas tecnologías en todo el período.

\section{AGRADECIMIENTOS}

Este artículo forma parte de los resultados del Proyecto I+D+I de Excelencia, PID2020-112844GB-100, “El gas en la Europa Latina: una perspectiva comparativa y global (1818-1945)", financiado por el Ministerio de Ciencia e Innovación del Gobierno de España y Fondos Feder.

Española de Patentes y Marcas (AH-OEPM). (Barca y Alayo, 2011, p.58)

10 Bernardo Puig Buscó (1857-1929) era ingeniero industrial de la promoción de 1881 de la Escuela de Barcelona y en 1925 fue elegido académico de la Real Academia de Ciencias y Artes de Barcelona.

11 Patente $\mathrm{n} 018800$ de 14-03-1896. AH-OEPM.

12 (Industria e Invenciones, 15-01-1898, p. 22), (Industria e Invenciones, 21-05-1898, 196), (Industria e Invenciones, 2-091899, p. 78), (Industria e Invenciones, 23-03-1901, p. 93-94).

13 Patente no 19607 de 07-09-1896 y patente no 21242 de 2707-1897. AH-OEPM.

14 Carlos Bosque Franco. Patente no 19385, 27-07-1896. José María Bosque Franco. Patente no 19242, 18-06-1896 y Patente no 18996,4-05-1896. AH-OEPM.

15 Industria e Invenciones, 5-11-1898, p. 178) (Industria e Invenciones, 25-03-1899, p.115) (Industria e Invenciones, 1706-1899, p. 234).

16 Patente no 23832, 20-02-1899. AH-OEPM.

17 Patente no 23590, 31-12-1898, AH-OEPM.

18 (Industria e Invenciones, 2-03-1901, p. 67)

19 (Industria e Invenciones, 10-08-1901, p.50)

20 Patente no 2779 de 13-05-1901. AH-OEPM.

21 Becquerel, E (1857), "Nota sobre el alumbrado eléctrico", Revista de Obras Públicas (tomo I), pp 207-209, p.209.

22 "La cuestión de la electricidad", Revista de Obras Públicas (1882, tomo 6), pp.66-69, p.68

23 "Los Generadores Gaulard y Gibbs", El Porvenir de la Industria (1887), p.140 


\section{BIBLIOGRAFÍA}

Alayo Manubens, Joan Carles; Barca Salom, Francesc X. (2011), La tecnología del gas a través de su historia., Barcelona, Fundación Gas Natural Fenosa, LID.

Alcover, José (1882), "Necrológica de Ventura Serra Crusells", Gaceta Industrial, 10 de mayo, p. 129.

Almirall, Nacho (2011), "Historia de la familia Bolíbar 17002011". En: Bolíbar. [en línea], disponible en: http://bolibars. blogspot.com/p/historia-de-los-bolibar.html, [consultado el 21/03/2021].

Baltà Moner, Jaume (2020), Personatges de la ciencia i la tecnología al Penedés. Segles XVIII-XXI, Vilafranca del Penedés, Foix Arts Gràfiques.

Barca Salom, Francesc Xavier; Alayo Manubens, Joan Carles (2011), "La tecnología utilizada en las fábricas de gas españolas", Quaderns d'història de l'enginyeria, XII, pp. 53-92. [en línea], disponible en: http://hdl.handle.net/2099/11716.

Barca Salom, Francesc Xavier; Alayo Manubens, Joan Carles (2019), "The Transfer of Technology between Gasworks in Spain". ICOHTEC-Katowice 2019, session: The circulation of technology and knowlegde in the gas industry.

Cabana, Francesc (2001), Fàbriques i empresaris, Barcelona, Diputació. Vol. 1.

Cano Pavón, José (s/f), "José Alcover Sallent", en Real Academia de la Historia. Diccionario Biográfico electrónico [en línea], disponible en: http://dbe.rah.es/biografias/19022/jose-alcover-sallent, [consultado el 21/03/2021].
Manjarrés, Ramón. de (1880), "El gas de corcho”, Gaceta Industrial, 25 de diciembre, pp. 342-343.

Pettenkofer, Max Joseph (1855), "Gaz au bois et à la turbe", Le Génie Industriel, 9, pp. 258-259.

Portela Marco, Eugenio (s/f), "José Alcover Sallent". En: La Web de las Biografías. MCM Biografias.com. [en línea], disponible en: http://www.mcnbiografias.com/app-bio/do/ show?key=alcover-sallent-jose, [consultado el 21/03/2021].

Pretel O’Sullivan, David (2009), “Invención, nacionalismo tecnológico y progreso: el discurso de la propiedad industrial en la España del siglo XIX", Empiria. Revista de Metodología de Ciencias Sociales. 18, julio-diciembre, pp. 59-83.

Castillo, Alberto del; RIU, Manuel (1963), Historia de la Asociación de Ingenieros Industriales de Barcelona (1863-1963), Barcelona, Asociación de Ingenieros Industriales.

Housseau-Muiron (1856), "Fabrication du gaz au moyen des eaux de savon". Le Génie Industriel, vol 11, pp. 190-191.

Puig, Bernardo (1903), “Gasógeno a producción continua de acetileno", Revista Tecnológico Industrial, abril, pp. 94-103, mayo, pp. 119-130.

Riera Tuèbols, Santiago (1988), L'Associació i el Col.legi d'Enginyers Industrials de Catalunya de la Dictadura a la Democracia (1950-1987), Barcelona, Associació d’Enginyers Industrials de Catalunya.

Santponç, Francesc (1818), "Máquina hidrostática que sirve para la formación y distribución de gas hidrogeno que ilumina las calles de Londres, plazas públicas y edificios", Memorias de Agricultura y Artes, abril, pp. 225-236. 